Os Estudos da Cultura Visual (ECV) constituem um campo teórico e metodológico que responde a um debate iniciado nos anos 70 e que reclama uma aproximação das práticas da visão, dos meios e das representações visuais a partir de uma perspectiva cultural. Este debate não responde a problemática de uma única disciplina, mas a uma conjuntura intelectual na qual, pela influência das propostas pós-estruturalistas, se revisa a epistemologia e metodologia de várias disciplinas dando lugar a um novo campo de conhecimento, híbrido, polimorfo e a-disciplinar. Palavras-chave: cultura visual, pós-estruturalismo, história cultural da arte. 


\title{
Elementos para una génesis de un campo de estudio de las prácticas culturales de la mirada y la representación
}

\author{
Fernando \\ HERNÁNDEZ
}

Los Estudios de Cultura Visual (ECV) constituyen un campo teórico y metodológico que responde a un debate iniciado en los años 70 que reclama acercarse a las prácticas de la visión, los medios y las representaciones visuales desde una perspectiva cultural. Esto debate no responde a la problemática de una sólo disciplina, sino a un coyuntura intelectual en la cual, por la influencia de los planteamientos postestructuralistas, se revisa la epistemología y metodología de varias disciplinas, dando lugar a un nuevo campo de conocimiento, híbrido, polimorfo y a-disciplinar.

Palabras clave: cultura visual, post-estructuralismo, historia cultural del arte. 


\section{La coyuntura intelectual de la que parten los Estudios de Cultura Visual}

Mirzoeff, en su página Web presenta una síntesis, en la línea mantenida en sus publicaciones sobre este campo (MIRZOEFF, 1998, 2003[1999]), de lo que para él significa la cultura visual. Sin entrar ahora en el contenido de su posicionamiento con el que ya he dialogado en otros trabajos (HERNÁNDEZ, en prensa $a, b)$, me interesa destacar una frase con la que abre su presentación:

A lo largo de una década, los críticos han utilizado el término de cultura visual para referirse a un amplio espectro de medios visuales más allá de los utilizados bajo los parámetros de las disciplinas académicas (p.ej. estudios de cine, historia del arte). Más recientemente, debido a los cambios en los medios visuales contemporáneos, la cultura visual ha comenzado a ser considerada como una perspectiva interdisciplinaria que permite aproximarse a la revalorización sin precedentes de la historia de los medios visuales modernos y postmodernos, bajo el impacto de los medios digitales y electrónicos.

He rescatado esta frase porque su autor, uno de los divulgadores más activos en los ECV, nos indica que este campo de conocimientos no puede considerarse como un fenómeno que aparece de la noche a la mañana. Por el contrario, tiene una trayectoria que, quizá por la novedad rizomática de sus problemáticas y la tradicional necesidad de distancia temporal, comienza a ser ahora reconstruida en algunas publicaciones (ELKINS, 2003; DIKOVITSKAYA, 2005). De aquí que las fuentes de las que se nutre esta perspectiva vengan de lejos, como se puede apreciar en la selección de autores de los dos 'readings' más divulgados en este campo.

Así en la recopilación de Mirzoeff (1998), en el bloque dedicado a la 'genealogía de la cultura visual', se recogen los siguientes textos: 'Óptica' de Descartes; 'Regímenes escópicos de la modernidad' de Martin Jay; 'La retórica de la imagen' de Roland Barthes; 'Modernidad y los espacios de la feminidad' de Griselda Pollock; 'El Museo de Arte Moderno' de Carol Duncum; 'Sobre la recolección de arte y cultura' de James Clifford y 'Una amnesia topográfica' de Paul Virilio. 
Elementos para una génesis de un campo de estudio de las prácticas culturales de la mirada y la representación

Por su parte, en la selección que realizan Evans y Hall (1999), en el bloque denominado 'Culturas de lo visual', se recogen los siguientes textos: 'La actitud natural' de Norman Bryson; 'La retórica de la imagen' de Roland Barthes; 'Arte, sentido común y fotografía' de Victor Burgin; 'El mito hoy' de Roland Barthes; 'Panopticismo' de Michael Foucault; 'La obra de arte en la época de la reproductividad técnica' de Walter Benjamin; 'La imagen-mundo' de Susan Sontag; 'La separación perfeccionada' de Guy Debord y 'The bottom line on plane one: squaring up to The Face' de Dick Hebdige. Trabajos todos ellos que nos permiten esbozar un itinerario intelectual que ponga de manifiesto la tesis de este artículo: la no adscripción disciplinar de los Estudios de Cultura Visual.

Aunque recurrir a los referentes permite detectar líneas y conexiones, mi propuesta para construir esta génesis -no me atrevo todavía a desarrollar un proyecto genealógico, aunque su punto de partida queda aquí esbozado-, es ir más allá de los autores puntuales o de las generalizaciones que señalan el reciente interés por lo visual (vinculado por ejemplo a los nuevos 'aparatos y tecnologías' de la visión) y por el proyecto de visualización de la modernidad (BREA, 2005). Una génesis que para su reconstrucción demanda recorrer diferentes e intrincados caminos.

Mitchell (2000a, p. 1-2), uno de los mentores de este campo de estudios, nos señala la importancia de cuestionar los límites disciplinares:

La revolución acontecida en este campo vasto e indeterminado conocido como 'teoría literaria', las nuevas aproximaciones filosóficas a la representación y la relación de ésta última con el lenguaje y los nuevos avances en la historia del arte han establecido los cimientos que nos permiten considerar a las realidades visuales (incluidos los hábitos cotidianos de percepción visual) como estructuras culturales que, como tales, son interpretables y legibles y, también, como mínimo del mismo interés para los estudiantes de la cultura que el que tienen los archivos tradicionales de producción textual y verbal. Desde un punto de vista práctico, ya no nos sorprende saber de sociólogos o de antropólogos que escriben sobre museos o sobre obras de arte, o encontrarse con profesores de literatura que durante sus clases pasan películas o 
diapositivas, o a historiadores del arte que imparten clases de lingüística, retórica y antropología y que llevan a sus estudiantes a centros comerciales y a museos de arte. En resumen, la división de las disciplinas humanísticas en campos 'verbales' y 'visuales', con lo visual en clara minoría, ha perdido vigor, al igual que la distinción entre arte con mayúscula y cultura de masas.

Además, las referencias que hace Mitchell a la teoría literaria, al giro lingüístico, la historia del arte y el giro cultural, son mojones que indican un camino a seguir a la hora de fijar los ámbitos que permitan esbozar la génesis institucional y académica del interés por la cultura visual. Sin olvidar que esta irrupción múltiple de lo visual en el campo de las Ciencias Sociales reclama un trabajo de investigación que va más allá de las finalidades de este texto. Sin embargo, voy a señalar algunas líneas que pueden explicar el marco intelectual de los antecedentes desde los que surge (si puede hablarse en estos términos causales), y que pueden servir de base para ulteriores investigaciones. Y para disipar apropiaciones académicas interesadas por parte de los miembros de una sola disciplina.

\section{Elementos para una génesis}

A estas alturas de la investigación en la historia y la sociología de las disciplinas, sabemos que los nuevos campos no son obra de un autor ni que se pueden localizar en un momento histórico. La autoría de un giro en el conocimiento, como nos enseñó Khun, siempre tiene antecedentes y contexto, es el resultado de múltiples esfuerzos y requiere un tiempo notable para que su aceptación se normalice.

En el caso de la cultura visual puede ser significativo señalar a quien se supone que utilizó primero esta denominación. Pero sin olvidar que otros autores ya trabajaban en esta dirección, y que la Modernidad está sembrada de aportaciones como las antes citadas que pueden considerarse antecedentes de lo que hoy es un giro cultural en el estudio de las representaciones, miradas, tecnologías y artefactos visuales. Por tanto, si me refiero a un origen es porque me interesa después señalar su contexto. 
Elementos para una génesis de un campo de estudio de las prácticas culturales de la mirada y la representación

A quien Evans y Hall $(1999$, p. 5) atribuyen por primera vez la denominación de 'cultura visual' como objeto de investigación fue a Svetlana Alpers quien, en 1972, fue también pionera en utilizar el término 'nueva historia del arte'. Esta constatación es relevante por más que Alpers no se haya sentido particularmente vinculada a escuela alguna, tal y como comentaba hace algunos años en una entrevista:

Sospecho de los programas y las denominaciones como 'la nueva historia del arte'. Me resisto al título. Hago mi trabajo y no soy consciente de que lo que estoy haciendo sea parte de la nueva historia del arte. Estudio arte. Algo que es difícil de hacer. Simplemente trato de hacerlo de la mejor manera que puedo (RUSSELL, 1988, p. 16).

En relación al sentido que da al término 'cultura visual', éste aparece en 1983 en la introducción de su libro 'El arte de describir. El arte holands en el siglo XVII', donde nos dice:

En Holanda la cultura visual era central en la vida de la sociedad. Se podría decir que el ojo fue tanto un medio básico de auto-representación y de experiencia visual como un modo de auto-consciencia. Si el teatro fue el campo en el que la Inglaterra de Isabel se representó a si y ante si misma de manera más completa, las imágenes juegan ese papel para los holandeses. La diferencia entre las formas revela mucho sobre la diferencia entre las dos sociedades. En Holanda, si miramos más allá de lo que normalmente es considerado que como arte, encontramos que las imágenes proliferan por todas partes. Están impresas en libros, tejidas en las telas de las tapicerías o en las en los manteles de lino, pintados en los azulejos, y por su puesto, cubren las paredes. Y todo es representado, desde los insectos a las flores de los nativos brasileños a tamaño natural a los arreglos domésticos de los habitantes de Ámsterdam. Los mapas impresos en Holanda describen el mundo y a la misma Europa (ALPERS, 1986 [1983]: xxv).

Posición sobre la que vuelve en 1996, en su respuesta al cuestionario sobre la cultura visual en la revista October donde nos dice:

Cuando, hace algunos años, escribí que no estaba estudiando la historia de la pintura holandesa, sino la cultura visual holandesa, intentaba algo concreto. Focalizar en las nociones sobre la visión 
(el mecanismo del ojo), en los instrumentos para hacer la imagen (el microscopio, la cámara oscura) y en las habilidades visuales (hacer un mapa y experimentarlo) como recursos culturales relacionados con la práctica de pintar" (ALPERS, 1996, p. 26).

Tal y como ella manifiesta, y nos recuerdan Evans y Hall (1999:5), la orientación específica que da a Alpers a la noción de 'cultura visual' parte de la naturaleza de su tema de investigación, que estaba relacionado con una cultura en la cual las estrategias visuales eran constitutivas de las maneras de mirar y representar un mundo cambiante. Cuestión a la que se refiere en la introducción del libro mencionado:

¿Cómo podemos entonces mirar el arte holandés? Mi respuesta ha sido verlo en sus circunstancias. Algo que se ha convertido en una estrategia familiar en el estudio de la literatura y del arte. Por apelar a las circunstancias quiero decir no sólo ver el arte como una manifestación social sino también ganar acceso a las imágenes a través de la consideración de su lugar, papel y presencia en la cultura (ALBERTS, 1986, p. xxiv).

Posición que de nuevo nos lleva a su respuesta al cuestionario de October: la holandesa era "una cultura en la cual las imágenes, en cuanto diferentes de los textos, eran centrales a la representación (en el sentido de formulación de conocimiento) o el mundo" (ALPERS, 1996, p. 26).

Es indudable que lo que se proponía Alpers no era ni acuñar un nuevo término ni redefinir la historia social del arte. Buscaba, en la línea abierta por Baxandall (con quien colaboraba) con 'Giotto y los oradores' (BAXANDALL, 1996 [1971]) y continuada al año siguiente con 'Pintura y vida cotidiana en el Renacimiento'(BAXANDALL, 1978 [1972]), el estudio de los modos de percepción, de un cierto sector de la población, por su influencia en el desarrollo de la forma de su época (...) (Sin embargo) su investigación de los modos de percepción no nos lleva $(\ldots)$

simplemente a una 'historia de la percepción' que sustituya a la historia del arte; pero establece unas categorías de interpretación histórica a partir de unas formas de ver que se basan en formas mentales, de su función práctica -como objetos- y comunicativa, como elementos básicos para la intelección, no sólo de la génesis 
Elementos para una génesis de un campo de estudio de las prácticas culturales de la mirada y la representación

de las obras sino también de la comprensión, respuesta y disfrute de ellas en el pasado y, a través de ellas, en el presente (MARÍAS, 1996, p. 151).

Lo que está planteando Alpers como cultura visual era una respuesta al programa de investigación, a la necesidad de renovar el método en la historia del arte, que en 1983 se refleja en el lamento de Bryson cuando declara:

Poca cosa podrá cambiar mientras no se haga un replanteamiento radical de los métodos utilizados por la historia del arte (...) Hoy día cada vez hay menos historiadores de arte que se aventuren fuera de su especialidad para hacerse las preguntas fundamentales: ¿qué es un cuadro?, ¿cuál es su relación con la percepción?, ¿con el poder?, ¿con la tradición?" (BRYSON, 1991 [1983], p. 14).

Una vez formulada esta necesidad, y después de reconocer la aportación perceptualista de Gombrich y de la teoría del signo de Saussure, Bryson se desmarca de ambos y señala un programa de investigación histórica que tiene relación con la línea en la que Alpers define su propuesta de cultura visual:

En la explicación perceptualista del arte, el espectador es tan inmutable como la anatomía de la visión, y mi argumento es que la insistencia en la psicología de la percepción, por parte de Gombrich y de otros, ha tenido por efecto la deshistorización de la relación entre el espectador y la pintura: la historia es el término que ha quedado suprimido (de aquí la imposibilidad, en las actuales condiciones, de una historia del arte verdaderamente histrica) (BRYSON, 1991[1983], p. 15).

Es entonces al contexto y al paisaje visual del espectador, su mirada (que al incorporar la dimensión cultural transforma el ver en visualidad como señala Foster (1988)) y a los artefactos de la visión a lo que se está refiriendo Alpers cuando habla de 'cultura visual'. Es el contexto de la mirada, en la línea señalada por Bryson, y que con anterioridad había planteado Baxandall, sobre el que Alpers plantea la necesidad de indagar sobre las maneras de mirar, el paisaje visual y el papel que en todo ello juegan los aparatos de la visión que amplían y fijan la mirada. Esta propuesta, como veremos a continuación, 
se inscribe en un debate más amplio en tiene lugar en Gran Bretaña en torno al contenido y los métodos de la historia del arte, así como al contexto de recepción, del que tanto el artista como los espectadores forman parte. Este debate no es una cuestión 'de' la historia del arte, sino que afecta a problemáticas que van más allá de una disciplina, como veremos en los siguientes apartados.

Una vez señalada esta primera instancia desde la que se localiza alguna de las problemáticas iniciales de la cultura visual, lo que pretendo a continuación no es otra cosa que situar y ampliar algunos de sus referentes, de manera que permitan dibujar el mapa de relaciones entre saberes que, desde mi punto de vista, sirven de fuentes a los ECV. Para este recorrido he tomado tres ejes conductores que son citados en diferentes publicaciones en términos de 'giros' que adoptan los estudios en Ciencias Sociales desde finales de la década de los 70: el giro interpretativo (HEYWOOD y SANDWELL, 1999), el giro cultural (FREEDMAN, 2000; DUNCUM, 2001) y el giro lingüístico (HALL, 1997). Y que se asocian a la 'nueva' historia del arte, los Estudios culturales y al Postestructuralismo.

Estas 'giros' no han sido elegidos de manera casual, sino que son señaladas por autores como Mitchell (2000b) o Mirzoeff (2003 [1999]). Mitchell (2000b) define la Cultura Visual como "el estudio de la estructura social de la experiencia visual", que se produce por la emergencia de una serie de disciplinas como la Nueva Historia del Arte, los Estudios literarios y de los medios de comunicación, los Estudios culturales, todo los cuales giran en torno a lo que Mitchell denomina como un 'cambio gráfico', frente a lo que se pregunta:

"¿Qué es la cultura visual esta nueva interdisciplina híbrida que relaciona la historia del arte con la literatura, la filosofía, los estudios sobre cine y de cultura de masas la sociología y la antropología?".

En los ECV la idea de cultura, según Mitchell, proviene de los Estudios culturales y la idea de lo 'visual' de los Estudios de cine y de la Historia del arte. De esta manera la visión no es sólo un acto de percepción, sino una forma de expresión cultural y de comunicación humana, no reducible a ser explicada 
en los mismos términos del leguaje hablado y escrito. Lo visual actúa como un espacio de interacción social y de definición de subjetividades en términos de clase, género, sexo, etnia,... Por eso, la cultura visual abarca un amplio espectro de experiencias visuales (desde las imágenes cotidianas a los objetos que vinculamos al placer o el horror estético).

Por su parte, Mirzoeff (2003 [1999]p. 12-13) considera que la cultura visual como una integración entre la Historia del arte y los Estudios de cine con una perspectiva intelectual característica de los Estudios culturales. Esta combinación ha llevado a considerar que los Estudios de Cultura Visual eran, simplemente, la entrada de los Estudios Culturales en la Historia del Arte. Lo que a todas luces, como ahora veremos, resulta una simplificación interesada.

\section{De cómo la historia del arte llega a la cultura visual}

Al estudiar las influencias que plantean el giro hacia ECV, uno de los referentes que nos encontramos es el de una nueva aproximación a la historia del arte. Especialmente la que emerge en Gran Bretaña a partir de finales de los años sesenta y que ha sido denominada como 'Nueva Historia del Arte'. El punto de partida de este movimiento, lo sitúan Ress y Borzello (1986: 3 ss.) en 1973, año en el que Timothy J. Clark publica dos estudios sobre la pintura del siglo XIX en Francia que tuvieron un notable impacto entre los jóvenes historiadores del arte británicos. Me refiero a 'The Absolute Bourgeois, artists and politics in France 1848-51' (CLARK, 1973) y 'The image of the people, Gustave Coubert and the 1848 Revolution' (CLARK, 1981 [1973]). En estas publicaciones, siguiendo una perspectiva marxista, Clark ponía en evidencia la relación entre las artes y la lucha de clases. Aunque la intención de mi propuesta está alejada de buscar explicaciones unicausales a los fenómenos sociales, no habría que perder de vista que T.J. Clark fue uno de los miembros de la Sección Británica de la Internacional Situacionista, de la que fue expulsado en diciembre de 1967 con los otros dos miembros de la sección, Christopher Gray y Donald Nicholson-Smith. 
Parece entonces relevante recordar que el libro "La sociedad del espectculo, de Guy Debord (1999 [1967]) fue publicado en ese mismo año y tuvo una clara influencia en el proyecto de historia social de Clark, como se manifiesta en su libro The Painting of Modern Life: Paris in the Art of Manet and His Followers (1985). Por otra parte, no hay que olvidar que la obra de Debord, es considerada como un antecedente del interés que cobrará la imagen y lo visual en una sociedad del espectáculo, de la representación, en la medida en "que todo lo que estaba vivo se ha transformado en una representación". Las imágenes, tal y como las considera Debord, han llegado a ser tan comunes que no sólo se funden con la realidad sino que comienzan a ser realidad. Las imágenes en la actualidad se refieren con frecuencia más que cualquier cosa previamente pensada a lo real. Debord considera que en las fases anteriores del capitalismo, se produjo un giro del ser a tener, mientras que ahora, en la sociedad del espectáculo el giro pasa del tener a aparecer (DUNCUM, 2001, p. 2).

Esta revisión del papel de la imagen en la sociedad contemporánea lo extiende Clark a épocas pretéritas, tal y como apunta en su Narrative of Career, en la que describe su trayectoria:

Desde el principio de mi carrera como estudiante estaba decidido a licenciarme en historia del arte, y en particular en encontrar un camino que pusiera en contacto la historia de la pintura con otras historias social, económica y política (la cursiva es mía). En 1964 me matriculé para el doctorado en el Courtauld Institute of Art de la Universidad de Londres, y en 1966-67 estuve en París como investigador del Centre Nationale de la Recherche Scientifique.

La influencia del pensamiento francés y de los acontecimientos sociales que se fraguaron durante la estancia de Clark en París, van a estar presentes en su propuesta para una nueva metodología de la historia del arte. De aquí que, en 1974, un año después de publicar las dos investigaciones mencionadas, Clark hace una llamada desde The Times Literary Suplement, publicación en la que ejercía como crítico, para llevar a cabo una historia del arte que tuviera en cuenta las realidades sociales del mundo en el que se producía el arte. En este sentido reclamaba 
Elementos para una génesis de un campo de estudio de las prácticas culturales de la mirada y la representación

un trabajo de teoría y práctica. Necesitamos hechos - sobre el patrocinio, el comercio del arte, el papel del artista, la estructura de la producción artística - pero necesitamos conocer qué preguntas platearnos sobre lo material. Necesitamos importar una nueva serie de conceptos, y llevarlos al método de trabajo (rf. por BIRD, 1986, p. 34).

La propuesta de Clark era llevar a cabo una historia social del arte reestructurada a partir tres ejes, que conectaban con otras tantas referencias teóricas francesas: (a) las recientes aportaciones desde de la teoría marxista, de manera especial desde las críticas post-Althusserianas a la subjetividad, (b) la atención al significado, considerándolo tanto como producción como proceso y definido desde de la Semiótica y (c) el interés en las determinaciones materiales e ideológicas sobre la producción y la recepción artística.

Esta llamada se concretó en 1975 en el terreno académi$\mathrm{co}$, en la Universidad de Leeds, donde dio comienzo un master en Historia Social del Arte, bajo la inspiración del propio Clark que era profesor de esa universidad. Esta tendencia se extendió sobre todo por los nuevos institutos politécnicos del Reino Unido donde, tal y como reconocen Evans y Hall (1999, p. 6), "el estudio cultural de la imagen ha formado parte de las pioneras licenciaturas de fotografía e historia del arte desde finales de los años 70".

Este proceso institucional se vio acompañado en 1979 por la aparición de la revista Block como foro para los nuevos historiadores en el campo del arte y del diseño. Los artículos que se publicaron, comentan Ress y Borzello, "hacen referencia más a lo que está pasando en Nanterre que en la National Gallery". La revista rompe moldes y publica ensayos fotográficos, collages y artículos escritos por artistas. En la editorial de presentación se señala la intención de "dirigirse a los problemas relacionados con la dimensión social, económica e ideológica de las artes en las sociedades pasadas y presentes" (BIRD, 1986, p. 32-33). Una finalidad que se mantiene constante durante los seis años en los que se publica la revista. Para Bird (1986: 35) Block no pretendía simplemente redefinir el estatus de la obra de arte y del sujeto artístico, sino criticar los marcos de trabajo 
epistemológicos del discurso de la historia del arte y desafiar su autoridad y estatus institucional

Una vez abierto el frente institucional y el de la visibilidad que se refleja en Block, no parece extraño que en 1980 The Association of Art Historians abriera su congreso y su revista Art History a contribuciones sobre metodología, feminismo e historia social. Al mismo tiempo que la nueva historia del arte va a comenzar a tener presencia en los módulos y créditos de la Open University.

Con el reconocimiento y la proyección institucional, en 1982 Block organiza en su sede del Middlesex Polytechnic un congreso bajo el interrogante ¿La Nueva Historia del Arte? siendo la primera vez que, en opinión de Ress y Borzello, se emplea en público tal denominación, al tiempo que constituye el reflejo de un cierto escepticismo sobre el propio nombre de la propuesta.

Lo que los nuevos historiadores del arte cuestionaban estaba relacionado con el estatus del arte, y la idea comúnmente aceptada de que arte quiere decir pinturas y esculturas ordenadas por estilos. Se preguntan cómo estos objetos y no otros han sido denominados "arte» y por qué sólo ellos han sido estudiados. Se preguntan a qué propósito sirven las personas que realizan esa tarea y quienes los miran en los libros, en las casas y los museos y galerías. El sujeto del arte es puesto bajo revisión y se preguntan por qué los pobres, los paisajes o las mujeres aparecen como lo hacen en la «representación» que el arte hace de ellos. El papel político y económico del arte en la sociedad contemporánea se dirige en particular, a lo que con frecuencia aparece camuflando las vinculaciones entre la academia y el mercado, y la utilización que del arte hacen los Estados y las empresas que están ansiosos por limpiar su imagen.

En este proceso se comienza a cuestionar la historia del arte tradicional y palabras como experto, cualidad, estilo y genios se convierten en tabú. Tales términos dicen Ress y Borzello (1986, p. 4-5), sirven para oscurecer todo un mundo de concepciones sobre lo que es arte. Las palabras que están presentes en los escritos de los nuevos historiadores del arte son ideología, patriarcado, clase, metodología y otros términos que tienen su origen en las Ciencias Sociales. Detrás de ellos hay una nueva 
Elementos para una génesis de un campo de estudio de las prácticas culturales de la mirada y la representación

manera de ver el arte, íntimamente vinculada a la sociedad que la produce y consume y alejada de ese algo misterioso que sucede como resultado del genio del artista.

¿Qué estaba aconteciendo para que se planteara este cuestionamiento de la historia del arte? Es importante recordar que en Gran Bretaña, en los ambientes universitarios tenían lugar debates en otras disciplinas, como la Lengua inglesa, donde la teoría dejó de ser una cuestión periférica para convertirse en lo esencial de la discusión. Estos debates llevaron a prestar atención a nuevas referencias teóricas, desde

la teoría lingüística de Althusser, Barthes y Derrida, a los modelos antropológicos e históricos establecidos por Michael Foucault, las teorías sociológicas de profesores como Jane Wolff y las teorías psicoanalíticas dentro de la zona cultural por parte de Lacan y otros escritores post-freudianos (POINTON, 1986, p. 151).

Por otro lado, comienzan a hacerse un espacio en la universidad y en los politécnicos de reciente creación, otros campos de estudio como la Historia del diseño, los Estudios de cine y en análisis de los medios de masas, que toman sus fundamentos de referentes disciplinares diversos. Pero, sobre todo había la necesidad, como indica Marcia Pointon (1986, p. 152) de revisar el fundamento disciplinar de la historia del arte que estaba

necesitada de una base teórica más rigurosa. Es precisamente la ausencia de teoría, tanto en el sentido de 'un esquema de ideas que explique la práctica' como en el de una hipótesis en oposición a la práctica, lo que con frecuencia determina que el estatus de la historia de arte como una disciplina haya sido puesto en cuestión. El aspecto arqueológico y empírico de la disciplina con su fuerte tradición en estudios de atribución, esto es, de connoisseurship, es necesario, pero ha jugado un papel dominante y opresivo, y la descripción y la impresión personal ha tomado con frecuencia el papel de un análisis serio.

Esta necesidad de una teoría fuerte que no estuviera separada del estudio histórico se vincula a un movimiento más amplio, nos recuerdan Rees y Borzello, cuyos términos habían sido formulados en 1968 por Perry Anderson, editor de New 
Left Review, en su ensayo 'Components of the National Culture' donde sostenía que la vida intelectual británica se había desarrollado sin una teoría central de la sociedad como la que había facilitado al resto de Europa el marxismo o la sociología burguesa clásica. Los intelectuales británicos en la tradición positivista, con su miedo a cualquier idea teórica, rechazaron cualquier opción en favor de perspectivas fragmentadas, eclécticas en sus disciplinas. Para redirigir ese vacío Anderson hacía una llamada a favor de una nueva intelectualidad radical que hiciera frente a la estrechez y conformismo de la cultura británica.

A este reto respondió a principios de los años 70 la revista de cine y medios de comunicación Screen. Esta publicación tuvo un amplio impacto en la vanguardia intelectual al promover las entonces poco conocidas ideas de los formalistas rusos y del círculo de Brecht-Benjamin, la introducción de la semióticas de Saussure a Barthes, y discutir el post-psicoanálisis de Jaques Lacan. Screen adoptó y adaptó el marxismo estructuralista de Louis Althusser y su 'riguroso' lenguaje. Estas ideas extrañas a la cultura británica se movieron dentro de ella a través de disciplinas como los Estudios de cine y de media, hasta que los cineastas de Screen mostraron su relevancia en la investigación académica. Todo lo anterior hace posible, como apuntan Ress y Borzello (1986, p. 5), que

la nueva historia del arte no fue una visión que tuvieron un grupo de heroicos historiadores que pasaron su fe a sus seguidores. Es un producto de la tolerancia de final de los años sesenta y de las ideas que en el continente europeo habían cambiado la naturaleza de las disciplinas académicas a lo largo de las dos últimas décadas junto a la expansión de la historia del arte como disciplina.

Una posición que lleva a Norman Bryson, uno de los entonces jóvenes historiadores del arte, a reclamar "un replanteamiento radical de los métodos utilizados por la historia del arte: los supuestos tácitos que guían la normal actividad del historiador del arte. Aquí quizá se pueda hacer algo, y la acción corre tanta prisa como retraso lleva" (BRYSON, 1991, p. 13). La posición de Bryson y de otros nuevos historiadores del arte la resume Marías (1996, p. 142) al señalar que 
Elementos para una génesis de un campo de estudio de las prácticas culturales de la mirada y la representación

han insistido en los últimos años de forma combativa, en las posibilidades de la unión de la Historia del Arte y la crítica del arte basada en las aportaciones más recientes de la crítica literaria y la semiótica de Roland Barthes. Han tachado a la historia del arte institucional de leer documentos más que imágenes, de basarse en el perceptualismo y una sociología que coloca en columnas diferentes arte e ideología y omitir el tema de su formación social, más que partir del concepto de signo; la imagen como signo, con sus denotaciones no naturales y con sus connotaciones que confirmarían y sustanciarían la denotación de tal forma que ésta parece alcanzar el nivel de verdad, incluiría el poder social y político, como signos socialmente construidos en el marco de códigos de reconocimiento.

Marcia Pointon revisa las consecuencias de estas influencias teóricas y metodológicas, en la medida en que los nuevos historiadores van a tener como una de sus tareas fundamentales la enseñanza en los politécnicos y universidades recién creadas.

En el tiempo pasado de la historia del arte, los profesores de la universidad podrían esperar o tolerar un debate interdisciplinar. Un debate que proporcionara datos por el estudio de un tema, es decir, iconografía, y acuerdos para el estudio de las culturas no occidentales o un proyecto concreto como los patronos en el siglo XVIII. Los recursos de diapositivas de la biblioteca se han organizado con esta base. Pero la ahistoricidad de los métodos actuales, desde el estructuralismo al psicoanálisis han enviado a los profesores y a los estudiantes en búsqueda de materiales visuales que nunca con anterioridad se ha encontrado en las sesiones de diapositivas de la biblioteca, organizado artista por artistas o escuela por escuela, siglo por siglo (POINTON, 1986, p.151-152).

El resultado de esta proceso de renovación de los fundamentos y las metodologías de la Historia del Arte lo refleja Marcia Pointon (1994 [1980]: p. ix) en el prólogo de la tercera edición de su manual de Historia del Arte:

Block ya no existe como revista pero sobrevive, y con buena salud, como una constelación de personas e ideas, vinculadas a instituciones como la Tate Gallery en la organización de actos culturales (...) La Historia del Arte está mejor establecida como disciplina en Gran Bretaña que hace ocho o diez años. Los estudiantes en la Europa continental se encuentran obligados a leer en inglés 
si quieren estar al día con la bibliografía; la revista Art History de la asociación de historiadores de arte ha incrementado su circulación; el número de estudiantes en las instituciones se ha doblado. $\mathrm{Si}$, en la recesión del inicio de los años noventa el mercado del arte decayó, esto fue algo que no pasó en el campo intelectual de la historia del arte. El tipo y la variedad de compromisos en el campo académico son impresionantes.

Todo ello nos lleva a compartir con Rogoff (1998, p. 20) que desde la cultura visual,

la historia pasa a ser la de visualizador (viewer) o la del discurso autorizado, más que la del objeto. Este giro plantea necesariamente un cambio en el sujeto de discusión o de análisis, un giro en el cual la necesidad de tener la discusión en primer lugar y por tenerla bajo un modelo metodológico y en un tiempo particular forma parte de esta discusión.

Esta conjunción entre conocimiento situado y análisis del discurso autoreflexivo acompañado por una historia consciente sobre el sujeto que ve (o sobre el tema visto), no parece que sea una base para ese lamento pesimista, simplemente es una oportunidad para un poco de auto-consciencia y un examen riguroso de las políticas inherentes a la evaluación de cada proyecto cultural.

\section{La Historia Cultural del Arte y los ECV}

¿En qué medida estos planteamientos para la historia del arte están presentes en los ECV? Responder a esta pregunta, como conclusión de este primer apartado no pretende ser exhaustivo, como tampoco lo ha sido el recorrido realizado. En todo caso, lo que se pretende es un esbozo de síntesis, que tenga un valor recapitulativo y que abre caminos para seguir investigando esta relación.

- Un carácter interdisciplinar en los fundamentos y las metodologías que procede de la mirada hacia referencias teóricas procedentes sobre todo del pensamiento francés (estructuralismo, semiología, teoría psiconalítica lacaniana, postestructuralismo o desconstrucción) de los años sesenta y setenta, a 
Elementos para una génesis de un campo de estudio de las prácticas culturales de la mirada y la representación

los que se unen otras perspectivas emergentes como la teoría feminista, la historia social, los estudios de los medios, la teoría post-colonial, ...

- La extensión del objeto de estudio más allá de los objetos considerados tradicionalmente como obras de Arte con mayúscula. En este sentido, Marcia Pointon destaca esta ampliación cuando nos recuerda que

Los que vivimos en las sociedades de estilo occidental, habitamos en un mundo de comunicaciones visuales: televisión, películas, vídeos, anuncios, señales de tráfico en entornos urbanos y rurales avisándonos y alertándonos, graffiti en edificios y vehículos, fotografías en periódicos, pinturas en gallerías de arte, tiras de dibujos y chistes, el empaquetado de los bienes de consumo. Ninguna de estas formas est fuera de la historia; todas estn determinadas por cmo vivimos e interactuamos con nuestros entornos as como con lo que aconteci en el pasado (la cursiva es mía). La cultura visual expande un amplio espectro de experiencias desde unos pantalones ajustados a un autorretrato de Rembrandt en la National Gallery (POINTON, 1994 [1980], p. 1).

- En esta misma línea tanto la Historia del Arte como la perspectiva de la cultura visual no se refiere sólo

a los artistas y sus obras, sino que también tiene (o debería tener) responsabilidad de tratar de comprender cómo y por qué el trabajo de algunos productores es discutido mientras que el de otros no, y por qué los artistas y su trabajo significan, o producen significados para la gente, de ciertas maneras, en ciertos periodos y en ciertos lugares. La historia del arte se dirige no sólo a cómo una obra de Leonardo se hizo y fue recibida en el tiempo que se realizó, sino por qué pensamos en Leonardo como Arte y un anuncio en una revista como No Arte (POINTON, 1994[1980], p. 3).

- Tanto la Historia cultural del Arte como los ECV ponen en relación diferentes tipos de imágenes y se plantean, por ejemplo, lo que un leonardo y un anuncio publicitario podrían tener en común (por ejemplo, el uso de la figura femenina). "Al considerar estos aspectos a lo largo de diferentes periodos históricos, se pueden encontrar referencias que puedan contribuir a nuestro conocimiento histórico" (POINTON, 1994[1980], p. 3). 
Pero no se trata de que la Historia del arte amplíe su campo de estudio. Para afrontar este proyecto cultural se necesitan referentes antropológicos y sociohistóricas que lo fundamenten. Porque como señala Jonathan Crary (1996:33-34) el problema histórico sobre la visión es diferente de una historia de los artefactos representacionales. Esto significa que la visión no puede separarse de las cuestiones históricas sobre la construcción de la subjetividad. Sobre todo dentro de la modernidad del siglo $X X$. Lo que hoy constituye el dominio de lo visual es un efecto de otro tipo de fuerzas y relaciones de poder, y no un hecho de carácter perceptivo. Esto nos lleva a que la experiencia estética ya no es posible reducirla a información, porque en la era de las imágenes hay más información tras nosotros que lo 'vemos'.

Todo lo cual nos conduce al siguiente eslabón de nuestro recorrido. A la revisión de las aportaciones que los Estudios Culturales desde el Centro de Estudios de la Universidad de Birmingham (CECB) tienen en el interés y los planteamientos de los ECV.

\section{El referente de los Estudios Culturales}

El CECB comenzó su andadura como parte del departamento de Lengua inglesa de la Universidad de Birgmingham, y su primer foco de interés fue llevar a cabo un proyecto de recuperación de la cultura, como un modo de vida global de la clase trabajadora, en lo que se llamó English Literature-based Workers Educational Association initiatives. Se sitúan, como señala Raymon Willians (1989), en los inicios del movimiento de educación de las personas adultas y de la revalorización de la cultura popular como parte de un proyecto de formación de sectores de la clase obrera.

Pero el centro inició su trayectoria más conocida en 1968, a partir de las iniciativas de su segundo director, Stuart Hall. Con Hall, el centro empezó una etapa de publicaciones como la revista bianual Working Papers in Cultural Studies y los Stencilled occasional papers que mostraban las investigaciones y preocupaciones teóricas de los miembros del centro. Su objetivo pasó a ser el desarrollo d un estudio crítico de las fuentes, dirección 
Elementos para una génesis de un campo de estudio de las prácticas culturales de la mirada y la representación

y significado del cambio cultural en Gran Bretaña y otras sociedades industriales avanzadas, y las fuerzas que dan forma al cambio.

Esto suponía alejarse del positivismo y afrontar la vinculación de sus investigaciones con una teoría central de la sociedad, vinculada a una "práctica crítica marxista" (HALL, 2000 [1992] : 12) relacionada con el debate abierto en Francia por Althusser, en su revisión del marxismo y del papel del sujeto en relación con la sociedad.

Pero en el CECB no se articula como una escuela monolítica que sigue una tendencia unidireccional. Como señala el propio Hall (2000 [1992]: 11)

"Ios Estudios culturales tienen discursos múltiples y caminos distintos. Son un conjunto de creaciones; responden a diferentes coyunturas y momentos trascendentes del pasado. Incluían trabajos de orientaciones muy diversas (...) a partir de una serie de metodologías y posiciones teóricas diferentes y en mutua controversia".

Desde esta consideración de pluralidad podemos acercarnos a los Estudios culturales en cuanto campo de encuentro de saberes, que desde diversas perspectivas teóricas y metodológicas, nos permiten explorar las nuevas realidades sociales en base a sus producciones culturales, desde una perspectiva de reconstrucción de los propios referentes culturales. Reconstrucción que no sólo es de carácter histórico, sino que se lleva a cabo desde lo emergente, desde lo que está aconteciendo, mediante la investigación que se apoya en el trabajo de campo o el análisis de textos e imágenes. Poniendo el énfasis en su función mediadora de identidades y relaciones y explorando las formas de representación y de producción de nuevos saberes y de formas de poder y control.

Estudios culturales tratan de exponer y reconciliar la división del conocimiento que tiene lugar en las Ciencias Sociales, entre las formas de conocimiento tácitos (el conocimiento intuitivo basado en las culturales locales) y las formas de conocimiento objetivos (también denominados universales). En esta reconciliación los Estudios culturales asumen que existe una identidad y un interés común entre el conocedor y lo que se conoce, entre el observador y lo que se está observando. 
Desde estas bases, los Estudios culturales desarrollan un programa de investigación sobre las prácticas culturales emergentes y su carácter mediador de identidades e ideología, desde una posición de compromiso con la evaluación moral de la sociedad moderna y con una línea radical de acción política. Los Estudios culturales no se constituyen como una escuela libre de valores, sino que están comprometidos con la reconstrucción social mediante la implicación crítica y política. De esta manera tratan de comprender y cambiar las estructuras de dominación, en particular de las sociedades industriales. Y lo hacen desde una perspectiva política, teniendo en el horizonte la metáfora del intelectual orgánico de Gramsci (1972) que sirve de referente para posicionarse frente al objetivo del proyecto social de los Estudios culturales. A partir de Gramsci, los debates, publicaciones e investigaciones del CECB buscaban promover en la teoría social un 'desplazamiento' desde el marxismo. Para ello, como recuerda Stuart Hall, tomaron

muchísimo acerca de la naturaleza misma de la cultura, acerca de la disciplina de lo coyuntural, acerca de la importancia de la especificidad histórica, acerca de la enormemente productiva metáfora de la hegemonía, acerca de la manera en que se puede reflexionar sobre cuestiones de relaciones de clase solamente por medio del concepto desplazado de conjunto y bloques (HALL, 2000 [1992]: 16).

Este posicionamiento se lleva a cabo desde dos tendencias fundamentales, que Hall (1980) denomina 'culturalismo' y 'estructuralismo'. El debate en ambos enfoques se centraba en el estatus que se le otorgaba a la experiencia. Para Hall "mientras en el 'culturalismo' la experiencia es el espacio, el terreno de 'lo vivido', en el que la conciencia y las condiciones de la experiencia se interseccionan, el 'estructuralismo' insiste en que la 'experiencia' no puede, por definición, ser el terreno de nada, en tanto que alguien sólo puede vivir y experimentar sus condiciones en y a travs de las categorías, clasificaciones y marcos de la cultura. Estas categorías, sin embargo, no surgen en la experiencia: sino que la experiencia es su 'efecto'.

Los culturalistas habían definido las formas de conciencia y cultura como realidades colectivos. Sin embargo, no se acer- 
Elementos para una génesis de un campo de estudio de las prácticas culturales de la mirada y la representación

caron a la propuesta radical de que en la cultura y en el lenguaje, las categorías de cultura en las que un sujeto piensa, hablan al sujeto, y no el sujeto 'habla de ellas'. Estas categorías no son, por tanto, meramente colectivas, sino producciones individuales: para los estructuralistas se articulan como estructuras 'inconscientes', contribuyendo a la configuración de la ideología.

No hay que perder de vista que estos planteamientos de Hall se formulan en torno a la 'revolución conservadora' del thatcherismo en Gran Bretaña y del reaganismo en Estados Unidos. Esto les lleva a interrogarse sobre la imposibilidad de comprender estas sociedades a través del racionalismo, o de una manera que no sea a través de la lógica de un sueño. Esto significa que los procesos culturales deben interpretarse en términos de procesos psicosexuales (una lógica contradictoria de seducción, violencia, agresión en la que el sujeto actúa según situaciones contractuales regidas por el cálculo de intereses). Con ello no se quiere decir que se trata de afirmar que los procesos políticos se rijan únicamente por procesos psicosexuales, sino a través de procesos inconscientes. Al tiempo que se reconoce que de los procesos inconscientes no puede derivarse directamente una relación con los procesos culturales y políticos. No pueden resumirse el uno en el otro. La ilusión racionalista de este tipo de traducción finaliza con el reconocimiento del inconsciente, que llega a los Estudios culturales por la vía del giro lingüístico y de la aproximación lacaniana, sobre todo a partir de la 'teoría del espejo' (LACAN, 1971[1996]).

Esta posición se vio reafirmada por el giro feminista que tuvo lugar en la década de los ochenta, porque reorganizó el campo de los Estudios culturales ampliándolo y propiciando rupturas con posiciones anteriores. Hall (2000[1992]: 18-19) señala las rupturas que aportó el giro feminista en los Estudios Culturales. En primer lugar, abrió el debate "sobre lo personal en tanto que político" lo que supuso "un cambio de objeto de estudio de los estudios culturales". En segundo lugar,

la expansión radical del concepto de poder, que hasta aquel momento había sido en buena parte desarrollada dentro del marco de lo público (...) tuvo el efecto de que ya no pudimos volver a uti- 
lizar el término poder de la misma manera. En tercer lugar, para la comprensión del poder mismo pasaron a un primer plano aspectos de género y sexualidad. En cuarto lugar, se abrieron muchas de las cuestiones que creíamos que habíamos eliminado en torno a la peligrosa área de lo subjetivo y el sujeto, y esta cuestiones se situaron en el centro de los estudios culturales como práctica teórica. En quinto lugar, se reabrió la frontera cerrada entre la teoría social y la teoría del inconsciente (psicoanálisis).

Con estas rupturas los Estudios culturales se abren, como nos recuerda Da Silva (1995) a las cuestiones que se derivan de la conexión entre cultura, significado, identidad y poder. Lo que hace que los 'objetos' que se estudian se consideren como resultado de un proceso de construcción social. Esto lleva a examinar su propio campo interdisciplinar en términos de prácticas culturales y de las relaciones de poder que circulan y que se reflejan en ellas. Su objetivo es hacer visibles las relaciones de poder y revisar cómo estas relaciones influyen y conforman prácticas culturales. También el en seno de los propios Estudios culturales (Sardar y Van Loon, 1998).

\section{El estudio de las prácticas culturales}

Uno de los objetivos de los Estudios culturales es el análisis de la cultura, entendida en la tradición de Raymond Williams (1976), como forma global de vida o como experiencia de un grupo social; como campo autónomo de la vida social, con una dinámica propia, independiente de otras esferas que podrían ser determinantes. Los Estudios culturales no son, por tanto, simplemente el estudio de la cultura considerada como una entidad discreta separada de sus contextos políticos y sociales. Su objetivo es comprender la cultura en toda su complejidad y analizar el contexto social y político dentro del cual se manifiesta. La cultura en los Estudios culturales realiza dos funciones: por un lado es el objeto de estudio y por otro, es la localización de la crítica social y política. Lo que significa que a la vez se proponen una tarea cultural y pragmática. Esta doble localización también aparece en la cultura visual que se constituye a la vez como lo que se estudia y como las perspectivas que la estudian. 
Elementos para una génesis de un campo de estudio de las prácticas culturales de la mirada y la representación

En los Estudios culturales la 'cultura' se considera tanto como 'forma de vida', lo que supone prestar atención a las ideas, actitudes, lenguajes, prácticas, instituciones y estructuras de poder, como 'prácticas culturales', es decir, formas, textos, cánones, mercadotecnia producida en masa,... O como señala Hall (1986: 26) "cultura significa el terreno real, sólido de las prácticas, representaciones, lenguas y costumbres de cualquier sociedad histórica específica, bien como las formas contradictorias del sentido común, que se enraízan en la vida popular y ayudan a moldearla".

El primer tema que se cuestiona en este acercamiento es la distinción entre la cultura de elite y la cultura popular. Distinción que, desde mi punto de vista marcará la orientación hacia los «márgenes» (expresión con reminiscencias de Derrida) de buena parte de quienes realizan investigación dentro de los Estudios culturales. Márgenes en los que se incluyen toda una serie de manifestaciones que la cultura de elite (centrada en los estudios de la literatura y los autores de los diferentes cánones, o en una historia del arte basada en movimientos, nombres y obras canónigas) había excluida de su interés y que se revelan necesarias para comprender las representaciones y actuaciones de los individuos en las sociedades contemporáneas.

Desde esta consideración de la cultura, los Estudios culturales formularon una amplia agenda sobre la cultura popular, con la finalidad de examinar las prácticas culturales específicas (historias, series de televisión, rock and roll), grupos sociales (juventud, equipos de fútbol femenino), prácticas o periodos de la cultura contemporánea, interesándose por las prácticas emergentes de las sociedades urbanas como las subculturas juveniles (punks, skaters) o el papel del fútbol en la cultura de la clase obrera, la imagen de la mujer en los medios de comunicación, las revistas femeninas,...

Uno de los primeros temas de interés fue acercarse a la comprensión de las representaciones simbólicas que intervienen en la vida de las personas y en las prácticas culturales. A cómo estas representaciones se producen mediante mecanismos culturales, aparatos institucionales y cómo son apropiadas y diseminadas a través de los discursos. En este planteamiento, tuvie- 
ron un papel relevante las aportaciones del trabajo semiológico de Roland Barthes (1970, 1981), sobre la función y la comprensión de la imagen, así como, en una primera fase, las aportaciones del estructuralismo lingüístico de Saussure. Otra inclusión importante fue la lectura estructuralista que de la constitución del sujeto por el lenguaje realiza el psicoanálisis lacaniano. La perspectiva lingüística tuvo mucha influencia en la construcción de una teoría feminista del arte y de la imagen, centrada en el estudio de la diferencia sexual a través de la interpretación del placer visual en la producción de las imágenes. Todo lo cual hace que uno de los objetos de investigación de los Estudios culturales sean las prácticas culturales, en las que lo visual, la visualidad y la representación juegan un papel importante.

\section{La conexión entre los Estudios Culturales y la Cultura Visual}

Es indudable que una de las contribuciones de los Estudios culturales ha sido poner en la agenda de investigación de las Ciencias Sociales la pertinencia de las prácticas culturales, sobre todo las vinculadas a la cultura popular, en cuanto mediadoras de identidades y subjetividades de clase, género, sexo y etnicidad. Una agenda que también tiene un papel relevante en el campo de la Cultura Visual.

Sin embargo, hay otro aspecto que resulta pertinente destacar, y es el papel que en los Estudios culturales británicos tienen en el 'giro lingüístico'. Lo que supone, en palabras de Stuart Hall (2000, p. 21), "el descubrimiento de la discursividad, de la textualidad".

Algo que "descentró y dislocó el camino trazado en el CECB", llevándole a lo que considera "un desvío necesario". Este giro tuvo lugar a partir del contacto de los miembros del CECB con los análisis estructuralista, semiótico y postestructuralista. Hall (2000, p. 21) señala esta relación en los siguientes términos:

la importancia fundamental del lenguaje y de la metáfora lingüística en todo estudio de la cultura; la expansión del concepto de 
Elementos para una génesis de un campo de estudio de las prácticas culturales de la mirada y la representación

texto y de textualidad, al mismo tiempo como fuente de significado y como lo que escapa al significado y lo pospone; el reconocimiento de la heterogeneidad, de la multiplicidad de los significados, de la lucha por cerrar arbitrariamente la infinita semiosis que hay más allá del significado; el reconocimiento de la textualidad y el poder cultural, de representación en sí mismo, como un ámbito de poder y regulación; de lo simbólico como fuente de identidad.

Como se ha señalado más arriba, la influencia del marxismo, lleva a reivindicar las manifestaciones culturales de las clases populares (como el fútbol o las telenovelas) y, más tarde, el postestructuralismo, conduce a temas hasta entonces marginales como 'la identidad', 'la representación' y 'la mediación' que van a tener un gran eco, sobre todo en los departamentos universitarios de Estados Unidos, donde son rápidamente institucionalizados y apropiados por los Estudios feministas, étnicos o de los medios.

Los análisis que lleva a cabo el CECB, nos recuerda Burgin (1996, p. 8), empiezan a tomar como referente las representaciones que aparecen en grandes medios de masas. Por ejemplo, Hall realiza un análisis de Picture Post, como una forma de 'autentificación' de cómo los británicos debían reconocerse como 'británicos'. El artículo de Hall contiene una crítica a la 'transparencia' que está presenta en todos los 'realismos' tanto en la Antropología cultural, como en el fotoperiodismo o el cine. Desde este punto de vista, señala Burgin "el objeto no es una 'gran obra' de la literatura sino un producto de los mass media, y al método analítico de la sociología se añade el de la semiología". De esta manera,

ya no es posible separar la cultura de masas, de la cultura popular y del 'gran arte'. En los niveles de producción y distribución, todos los trabajadores culturales dependen en gran parte de las mismas tecnologías e instituciones y todos los productos están igualmente sujetos a la mercantilización (a pesar de que sus relaciones específicas con el mercado varíen). Al nivel de la recepción, los significados de todos los productos de la cultura contemporánea tienden a estar cortados por el mismo patrón: tejidas desde la intertextualidad corrientes de sentido interrelacionadas aunque institucionalmente heterogéneas, surgen en diferentes momentos y lugares. De la misma manera que ya no existen espacios de producción 
cultural separados, no pueden existir islas de pureza contrahegemónica. A pesar de las afirmaciones de los populistas culturales o de los culturalmente conservadores, no se debe celebrar ni condenar la cultura visual de masas. Tampoco sirve para simplemente expresar o reprimir las aspiraciones y los deseos populares, sino que está complejamente implicada en su producción y articulación (BURGIN , 1996, p. 20).

Durante los años 70 y 80, influenciados por la preocupación por el lenguaje en el sentido apuntado por el postestructuralismo que veremos a continuación, la trayectoria de los Estudios culturales ya no se preocupará tanto del realismo y la transparencia, sino de los modos de representación. La introducción de los planteamientos de Roland Barthes será clave pare este giro lingüístico de los Estudios dulturales. La lectura de 'Elementos de Semiologa' (1979) y de 'Retrica de la Imagen' (1981), publicados ambos en Communications, y cuya versión inglesa aparecerá en el primer número de Working Papers in Cultural Studies, fue fundamental para el giro lingüístico al que más arriba se refería Hall. En este contexto también la imagen recibe una atención importante. Las imágenes son tanto una fuerza material en y entre las sociedades como una fuerza política y económica. La cultura visual contemporánea - el producto combinado de 'los medios' y la variedad de las otras esferas de la producción de la imagen - no pueden ser simplemente el 'reflejo' o 'comunicación' del mundo en el que vivimos: contribuye a la construcción de este mundo. Los individuos y las naciones actúan de acuerdo con creencias, valores y deseos que cada vez están formados e informados, conjugados y refractados,.. a través de imágenes.

Esta perspectiva afectó directamente a los estudios en relación al cine, especialmente a través de Christian Metz. Uno de sus artículos, se publicó en el mismo número de Communications en el que aparece el trabajo de Barthes, 'La Retórica de la imagen'. Según Burgin (1996), los análisis de la imagen en movimiento superaron los análisis de la fotografía, pues su aportación teórica fue más amplia. Prueba de ello es la publicación de la revista Screen, a la que me he referido anteriormente, que empezó a oponerse ampliamente a las versio- 
Elementos para una génesis de un campo de estudio de las prácticas culturales de la mirada y la representación

nes 'constructivistas' del realismo, como las de Bertolt Bretch, Walter Benjamin y los primeros cineastas soviéticos y a las asunciones 'naturalistas' que entonces prevalecían en el cine. Más adelante Screen incorporó la teoría psicoanalítica para explorar cuestiones políticas y de representación. Perspectivas que unían una mirada psicoanalítica con una mirada feminista. Por ejemplo el ensayo de Laura Mulvey (1971) 'Visual Pleasure and Narrative Cinema' va a abrir la puerta a uno de los temas cruciales en los estudios de medios y en la propia cultura visual: las políticas del placer en relación con la imagen por parte del sujeto que mira. Cuestión que se relaciona con la persuasión, pero también con el placer que la imagen (y quien la produce o crea) pretende y proporciona y que, al mismo tiempo, posiciona al espectador.

Todo ello va a suponer una nueva ampliación teórica de los Estudios culturales que corre paralela a la época a la New Left Review, que en 1968 publica un ensayo de Lacan que versa sobre la 'fase del espejo'. La conversión al psicoanálisis especialmente el desarrollado por Lacan, tenía la finalidad de proporcionar al Marxismo la visión que le faltaba sobre la producción del sujeto en el lenguaje. Esto suponía asumir que de la misma manera que nosotros utilizamos el lenguaje para hablar, el lenguaje nos 'habla'. Las prácticas sociales están estructuradas como lenguajes, y 'crecer' tiene lugar en un complejo de estructuras que producen, tanto como son producto de, agentes en el proceso político. Esta revista fue el reflejo de un movimiento que, como nos recuerda Hall,

siempre vio al marxismo como un problema, un inconveniente, un peligro, no una solución", en la medida en que, después de la invasión rusa de Hungría primero y de Praga después, la Nueva Izquierda británica vivía "el momento de desintegración de un proyecto histórico y político completo". En este sentido, lo que importaba no era tanto la agenda del marxismo, sino "los grandes desajustes, teórica y políticamente, los clamorosos silencios, las grandes evasiones del marxismo; las cosas acerca de las que Marx no habló o que pareció no entender, que fueron nuestro objeto específico de estudio: cultura, ideología, lenguaje, lo simbólico (HALL, 2000:13). 
También la noción de ideología de Marx, nos recuerda Burgin (1996, p. 11) fue desplazada por la de Althusser, que planteaba que la ideología era "un sistema de representaciones". La ideología, "ya no se ve como una 'falsa conciencia' (un epifenómeno dependiente de la economía política), la ideología se teoriza como una esfera de lucha política 'relativamente autónoma'. "En verdad", escribió Althuser -citado por Burgin-, "la ideología tiene poco que ver con la 'conciencia'.... Es profundamente inconsciente". En el desarrollo de los Estudios culturales, la posición frente a la ideología va más allá del análisis de Althusser. Stuart Hall $(1996$, p. 7) la sitúa en los siguientes términos: "si la ideología es efectiva es porque opera a la vez en los niveles rudimentarios de la identidad psíquica y sus mecanismos y en el nivel de la formación y las prácticas discursivas que constituyen el campo social".

\section{¿En qué medida los planteamientos de los Estudios Culturales están presentes en los ECV?}

Michael ha señalado que algunos consideran a los ECV como la concreción a la hora del estudio de la imagen y la representación del proyecto de los Estudios culturales. Aunque esta es una afirmación demasiado simplista -igual que lo es decir que es un desplazamiento de la Historia del Arte hacia el estudio de la cultura de las imágenes-, sí es cierto que tanto el giro cultural como el lingüístico marcan algunas de las investigaciones que pueden articularse en torno a los ECV. Pero no termina aquí la relación por lo que procede a hacer una recapitulación que muestre otros temas de contacto e intersección.

- El papel que se le otorga a la cultura, no sólo como contexto sino como señala Raymond Willians, como "forma global de vida o como experiencia de un grupo social; como campo autónomo de la vida social, con una dinámica propia, independiente de otras esferas que podrían ser determinantes". En esta forma de vida las imágenes y las maneras de mirar y los artefactos de la visión tienen un papel relevante. 
- La atención que se le presta a lo emergente en la cultura visual con la finalidad de comprender su función mediadora de identidades, subjetividades y relaciones sociales. En este análisis, que en la cultura visual es sobre todo semiótico y discursivo, la comprensión del papel de las representaciones en la producción de nuevos saberes y formas de poder y control constituye una referencia fundamental.

- El interés por las manifestaciones de la cultura popular, en especial de las producciones de los medios de comunicación, con la intención de explorar e interpretar sus significaciones como por la función ideológica en los diferentes tipos de audiencias.

- El papel que se le otorga a la imagen como forma de representación que se analiza en términos de significado y de constitución de signo, tanto en sí misma, como por parte de los diferentes espectadores. En este sentido, la aportación del análisis semiológico, pasado por los Estudios Culturales, llega al campo de la cultura visual, con un marco conceptual elaborado, unas herramientas metodológicas a punto y unos ejemplos que pueden servir como referencia.

- Todo ello sin olvidar, que una de las principales tareas de los ECV es comprender cómo esas imágenes se relacionan. Y en qué medida no son creadas desde un medio o un lugar, con las estrictas divisiones que la academia suelen mantener. La cultura visual dirige nuestra atención más allá de los escenarios visuales formales y estructurados, como el cine o el museo y coloca la centralidad de la experiencia visual en la vida diaria.

En el siguiente apartado voy a explorar el papel que el Postesctruturalismo, en sus diferentes vertientes, brinda a los Estudios de Cultura Visual.

\section{Un mapa sobre los 'poststructuralismos' y sus conexiones con los ECV}

No trato de realizar un recorrido extenso sobre la significación, aportaciones e influencias de los autores situados bajo el paraguas del Postestructuralismo, ni de su papel en el giro 
lingüístico y cultural que opera en las Ciencias Sociales a partir de finales de los años sesenta del pasado siglo. El lector puede encontrar una amplia bibliografía al respecto en diferentes páginas $W_{e b}{ }^{2}$. De estos autores, mi interés se centra en los que han dedicado una parte de sus ensayos ("género ambiguo donde la escritura disputa con el análisis" tal y como lo definió Barthes, 1974:113) a lo visual y a la imagen, entre los que cabe señalar, como sugieren Evans y Hall (1999:1) "el trabajo de Barthes, Benjamin ${ }^{3}$, Lacan y Foucault con sus claras preocupaciones visuales, por no mencionar a otros autores, constituye los fundamentos canónigos sobre los que descansan buena parte de los estudios culturales y de los medios". Lo que pretendo es presentar algunas referencias que ayuden a situar los rasgos de esta corriente de pensamiento, sobre todo en su relación con el lenguaje, la representación y la teoría cultural, dado que constituyen una fuente de la que se nutre los ECV.

De entrada, hay que señalar que la corriente de pensamiento postestructuralista no es unitaria ni se mueve en una sola dirección. Actúa, como señala Baross (1993: 158), en un espacio de frontera en el que con frecuencia se encuentra con el 'postmodernismo' (Baudrillard, Lyotard), la 'postcrítica' (Jameson) y la 'desconstrucción' (Derrida). Esta idea no unitaria también la señala Callinicos (1988:265) en un artículo donde lo define no como un enclave o campo disciplinar, sino como la confluencia de dos líneas distintas de pensamiento pero relacionadas entre ellas. Una denominada 'textualismo' y la otra, del 'conocimiento del poder' o como la nombra Edward Said, del 'postestructuralismo mundano' (CALLINICOS, 1988:265). También Hall (1990: 6-7), establece una distintición entre lo que denomina la perspectiva semiótica (Saussure) que "(...) se refiere a cómo la representación, a cómo el lenguaje produce significado" y la perspectiva discursiva (Foucault) que "(...) tiene que ver más con los efectos y consecuencias de la representación" y que ha tenido influencia "en cómo las ideas son puestas en práctica y utilizadas para regular la conducta de los otros".

El 'textualismo', escribe Callinicos (1988: 266-267), se refiere esencialmente al trabajo de Jacques Derrida y sus seguidores, de manera especial en Estados Unidos. Perspectiva que 
Elementos para una génesis de un campo de estudio de las prácticas culturales de la mirada y la representación

Rorty considera como heredera del idealismo clásico alemán, con la salvedad de que

mientras el idealismo del siglo XIX quiso sustituir una clase de ciencia (la Filosofía) por otra (las Ciencias naturales) como el centro de la cultura, el textualismo del siglo XX quiere poner la literatura en el centro y tratar a la ciencia y a la filosofía como, en el mejor de los casos, géneros literarios (RORTY, 1982, p. 141).

Sin embargo, en la observación de Rorty, el Postestructuralismo se mueve en una sola dirección y no considera el que adopta como categoría principal 'conocimiento del poder' de Michel Foucault. La diferencia entre la genealogía foucaultiana y el textualismo se pone claramente de manifiesto en la noción de Foucault (1980, p. 194) de 'dispositif' o aparato constitutivo del cuerpo social. Este aparato social estaría conformado por conjunto heterogéneo consistente en discursos, instituciones, formas arquitectónicas, decisiones reguladoras, leyes, medidas administrativas, afirmaciones científicas, proposiciones filosóficas, morales y filantrópicas. Pues no hay que olvidar que el proyecto de Foucault consiste en

trazar una historia de las diferentes maneras en que, en nuestra cultura, los hombres han desarrollado un saber sobre sí mismos: economía, biología, psiquiatría, medicina y penología. El punto principal no consiste en aceptar este saber como un valor dado, sino en analizar estas llamadas ciencias como 'juegos de verdad' específicos, relacionados con técnicas específicas que los hombres utilizan para entenderse a sí mismos (FOUCAULT, 1990, p. 47-48).

Mientras que el textualismo niega la posibilidad de escapar de lo discursivo, el rasgo característico de este postestructuralismo 'mundano' es su articulación, como señala Foucault, de "lo dicho y lo no dicho", de lo discursivo y lo no discursivo. Esta versión del postestructuralismo no sólo se ha de considerar asociada a Foucault, sino también a Gilles Delenze, Felix Guattari, Jacques Donzelot, entre otros autores. Pero no hay que perder de vista que estas dos perspectivas mantienen una importante relación. Como señala Callinicos (1988), ambas tendencias ofrecen una serie de teorías (del texto), críticas (de las instituciones), nuevos conceptos y formas de análisis (del poder y de 
los textos) que considero están presentes en los ECV. De aquí que no resulte extraño, que la mayoría de quienes investigan o tratan de definir el campo de la cultura visual señalen puentes con los autores como Derrida, Barthes, Lacan, Lyotard y Foucault. Una de estas vinculaciones nos la brinda Mirzoeff (2003, p. 6-7) cuando nos recuerda que

la cultura visual es nueva precisamente porque se focaliza en lo visual como lugar donde los significados son creados y debatidos. La cultura occidental ha privilegiado el mundo hablado como la más alta forma de práctica intelectual y ha considerado las representaciones visuales como ilustraciones de las ideas de segundo nivel.

En este sentido, la emergencia de la cultura visual desarrolla lo que Mitchell ha denominado "teoría de la imagen" (picture theory), con la que se refiere al sentido, a la visión del mundo, que adoptan algunos aspectos de la filosofía y la ciencia occidental, que son más imagen (pictorial) que textual. De aceptar cambio, constituye un desafío a la noción del mundo como un texto escrito que ha dominado la discusión logocéntrica y alfabetizadora (KRESS, 2003). En la perspectiva de Mitchell, la teoría de la visión proviene de

la realización que el visualizador ('spectatorship') (que se relaciona con mirar, ver, ojear, las prácticas de observación, vigilancia y placer visual) puede tener tanto en profundizar un problema como en varias formas de 'leer' (reading) (que se relaciona con descifrar, decodificar, interpretar, etc.) y que la 'experiencia visual' o 'la educación visual' pueden no explicar completamente desde el modelo de textualidad (MITCHELL, 1994, p. 16).

Aunque quienes trabajan en los medios visuales, señala Mirzoeff,

pueden encontrar estas consideraciones como paternalistas, ofrecen la medida de la extensión a la que han llegado los estudios literarios, en la que el mundo-como-un-texto ha sido reemplazado por el mundo-como-una-imagen (picture). Tales imágenes-mundo (world pictures) pueden no ser puramente visuales, pero por el mismo criterio, lo visual desbarata y desafía cualquier intento de definir la cultura puramente en términos lingüísticos" (MIRZOEFF, 1999, p. 7). 
Elementos para una génesis de un campo de estudio de las prácticas culturales de la mirada y la representación

De aquí que los conceptos conocidos como 'significantes diferenciados' o 'el inacabable juego del significado' actúen como elementos clave en el proceso de desconstrucción, que es una modalidad de crítica y análisis postestructuralista. En esta dirección, propuestas como las de Keith Moxey (1994) han redefinido una teoría del signo en la que considera al 'interpretante' de Peirce como nuevo 'signo' creado por el intérprete en el proceso de entendimiento de los signos, apoyándose en la teoría de la estructura 'dialógica' de lenguaje de Mijail Bajtín (1895-1975). Concretamente en su idea de que son los individuos los que se intercambian unos signos que entrarán a formar parte de la ideología. Además de en la teoría de la recepción (HOLUB, 1984), desde la perspectiva de Hans Robert Jauss (1986; 1991), quien explica el acto de leer como un proceso de una gran complejidad, de carácter intersubjetivo, social hasta un cierto punto y, al mismo tiempo, individual. Esto lleva a que la recepción de una obra (literaria, pero que se hace extensivo a la cultura visual) en el marco que Jauss y la escuela de Constanza han planteado, se configura como la mediación entre el pasado y cada presente (del lector) y, por lo tanto, ha de ser la auténtica materia de la historia de la literatura (LYNCH, 1988). Ampliando, además, el concepto de ideología (desde el pensamiento de Karl Mannheim), como elemento de la vida de todos los grupos y no sólo de sus clases sociales, que ni siquiera es compartida globalmente por todos sus integrantes - una vez que ha ha incorporado nociones de raza, género, sexo, etc.

Asimismo, la teoría de la mirada de Lacan (1971) (filtro, en el campo de la visión, similar al del lenguaje de lo simbólico), ha insistido en la relación entre representación y espectador. En la que éste se 'sitúa' visual y psíquicamente en función de la construcción de aquélla, como signo que a su vez negaría una concepción perceptualista-ilusionista de la imagen. Incluso frente a la teoría del la muerte del autor (Barthes) y del artista, al preexistir a su intervención las convenciones del código, con la consiguiente disolución del autor en su producto y la negativa a buscar las intenciones del artista en el acto interpretativo, establece un puente con Foucault en el carácter histórico de la 
subjetividad y en la necesidad de contar con ella en los contextos históricamente pertinentes.

\section{El papel del significado más allá de los límites del estructuralismo}

El Postestructuralismo tiene su base en la noción estructuralista de que el mundo está configurado como un texto. De aquí que cuando se habla de 'textos' de la cultura visual se esté planteando en clave postestructuralista. Lo que lleva a aceptar que el lenguaje es el lugar del significado y a considerar que el proyecto estructuralista no va suficientemente lejos en su estudio del lenguaje, es decir, que falla a la hora de analizar la estructuralidad de la estructura. Además, de considerar que el objetivo estructuralista de descubrir las reglas por las cuales los significantes codifican la realidad resulta baladí dada la variada naturaleza del lenguaje. Para ilustrar esta cuestión podemos ir al significante 'pintura'. Cuando se lee o se escucha la palabra 'pintura' viene a la mente la imagen mental que cada cual se forma. Que puede ser un cuadro, un lienzo, una tela, un color, un retrato, un paisaje, un fresco e incluso vincularse al maquillaje. Uno no piensa en una imagen esencial de 'pintura', como algo que es común a todas las personas que reaccionan al significante. Lo que nos lleva a concluir que los significantes no definen de manera unvoca los significados y a plantearnos, como nos recuerda Hall

que el significado no es directo ni transparente, y que no sobrevive intacto el paso a través de la representación. Es una práctica resbaladiza, cambiante y mudable con el contexto, utilización y circunstancias históricas. Por lo tanto, nunca acaba por estar definitivamente fijado. Se escapa siempre de encontrarse con la Verdad Absoluta. Está siempre en negociación con las nuevas situaciones. Es con frecuencia contestado, y algunas veces agriamente cuestionado. Hay siempre diferentes circuitos de significado circulando en cualquier cultura, superponiendo formaciones discursiva, a partir de las cuales creamos significado o expresamos lo que pensamos (HALL, 1997, p. 9-10). 
Elementos para una génesis de un campo de estudio de las prácticas culturales de la mirada y la representación

Por otra parte, no tenemos una relación directa, racional o instrumental con los significados. Estos movilizan sentimientos y emociones poderosas, tanto de tipo positivo como negativo. Sentimos su impulso contradictorio y su ambivalencia. A veces ponen nuestra identidad en cuestión. Definen lo que es 'normal', quien pertenece a esa normalidad, y también quien es excluido. Están profundamente inscritos en relaciones de poder. Sólo hay que pensar en qué medida nuestras vidas están moldeadas, dependen de los significados de hombre/mujer, blanco/negro, rico/pobre, homosexual/heterosexual, joven/viejo, ciudadano/extranjero, y el papel que juegan en muchas circunstancias. Los significados están, con frecuencia, organizados en opuestos binarios. Sin embargo, estos binarios están de manera constante siendo indeterminados, pues como representaciones interactúan uno con otro, substituyéndose, desplazándose a lo largo de una cadena sin fin. Nuestros intereses materiales y nuestros cuerpos pueden ser llamados en consideración, y pueden implicarse de manera diferente, dependiendo de como el significado es dado y tomado, construido e interpretado en diferentes situaciones. Pero de la misma manera están vinculados nuestros miedos y fantasía, los sentimientos de deseo y de repulsión, de ambivalencia y agresión. Cuanto más miremos en ese proceso de representación, más complejo resulta describir o explicar de manera adecuada.

Los conceptos, ideas y emociones que cobran cuerpo de manera simbólica y que pueden ser transmitidos y significativamente interpretados en lo que denominamos 'prácticas de representación'. El significado debe entrar al dominio de estas prácticas, si ésta circula de manera efectiva en la cultura. Y no puede ser considerado haber completado su 'pasaje' en torno al circuito cultural antes de que haya sido 'decodificado' o sea recibido de manera comprensiva en otro punto de la cadena. Lenguaje, es entonces, la propiedad no del emisor ni del receptor de los significados. Es el 'espacio' cultural compartido en el cual la producción de significado a través del lenguaje - esto es la representación - tiene lugar. El receptor de los mensajes y los significados no es una pantalla pasiva en la cual el significado original se proyecta de manera directa y transparente. La 
'toma del significado' es tanto una práctica significativa como 'la comunicación del significado',

Ya Charles Sanders Peirce (1839-1914) había sostenido la existencia en el signo de una relación triádica, frente a la diática de Saussure de significante/significado en la que aparecen unidos por una relación convencional de tipo social. Para Peirce los términos de la relación son signo, objeto (referencial) e interpretante, siendo este último el que estable la relación entre los otros dos. Del intérprete se derivarían tres tipos de signo, el símbolo 'arbitrario', el índice 'causal' y el icono en el que se daría una relación de semejanza (MARÍAS, 1996, p. 137-138).

Es por ello que, el que habla y escucha o el que escribe o lee es participante activo en un proceso en el cual, dado que a menudo cambian de papeles, es siempre de doble dirección, siempre interactivo. La representación funciona menos como el modelo de transmisor de una sola dirección, y más como el modelo de diálogo, dialgico. Lo que sostiene el diálogo es la presencia de códigos culturales compartidos, los cuales no pueden garantizar que los significados permanezcan siempre estables. Debido a los intentos de fijar el significado es exactamente porqué el poder interviene en el discurso. Pero incluso cuando el poder está circulando por el significado y el conocimiento, los códigos solo operan si comparten algo, al menos para garantizar que hacen posible una 'translación' efectiva entre los hablantes. Deberíamos quizá pensar menos en el significado en términos de 'precisión' y 'verdad' y más en términos de intercambio efectivo, en un proceso de traduccin, el cual facilite la comunicación intercultural, reconociendo siempre la persistencia de diferencia y poder entre los diferentes 'hablantes' en el mismo circuito cultural (HALL, 1997, p. 10-11).

\section{¿Dónde se produce el significado?}

Una vez establecidas estas clarificaciones, parece pertinente, sobre todo para establecer puentes con los problemas que 
Elementos para una génesis de un campo de estudio de las prácticas culturales de la mirada y la representación

aborda la perspectiva de los estudios de cultura plantearse, como hace Stuart Hall (1997), dos preguntas ¿cómo el lenguaje construye significados? y, sobre todo, ¿dónde se produce el significado? A la primera de estas cuestiones Hall responde diciendo que el lenguaje puede construye significados en base a los intercambios de los sujetos que comparten comprensiones intercambiables, porque opera como un sistema representacional.

En el lenguaje utilizamos signos y símbolos -que pueden ser tanto sonidos, palabras escritas, imágenes electrónicas, notas musicales, y objetos- para mostrar o representar a otras personas nuestros conceptos ideas o sentimientos. El lenguaje es uno de los 'medios' mediante el cual nuestros pensamientos, ideas o sentimientos son representados en un cultura. La representación por medio del lenguaje es, por tanto, central en el proceso mediante el cual se produce el significado (HALL, 1997, p. 1).

Desde esta posición una perspectiva de investigación a desarrollar podría consistir en explorar la producción y circulación de significados a través de diferentes lenguajes, en relación con diferentes ejemplos, en diferentes áreas de la vida social. De lo que se trata con ello es de desarrollar nuestra comprensión sobre como la representación opera con diferentes medios, para diferentes sujetos y en diferentes contextos y momentos.

A la segunda pregunta, ¿dónde se produce el significado? ${ }^{4}$ Hall responde que los significados se producen en diferentes lugares y circulan a través de diferentes procesos y prácticas (el circuito cultural).

El significado es lo que nos da un sentido de nuestra propia identidad, de quien somos a quién o qué pertenecemos. Lo que se vincula a cómo la cultura se utiliza para marcar y mantener identidad en y a diferencia de otros grupos. El significado se produce e intercambia de manera constante en cada interacción personal y social en la que tomamos parte. También se produce en diferentes media; en particular en estos días, en los denominados medios de masas, los medios de la comunicación global, mediante complejas tecnologías, que hacen circular significados entre diferentes cultura a una escala y velocidad desconocidas en otros momentos de la historia (HALL, 1997, p. 3).

El significado también se produce en cualquier momento en 
el que nos expresamos, usamos, consumimos o nos apropiamos de 'objetos culturales'; cuando los incorporamos en los rituales y prácticas de la vida diaria y de esta manera les damos valor o significación. O cuando tejemos narrativas, historias y fantasías en torno a ellas. Los significados también regulan y organizan nuestra conducta y nuestras prácticas, en la medida en que ayudan a fijar las reglas, normas y convenciones mediante las cuales la vida social es ordenada y gobernada. Esto hace que quienes quieren gobiernan y regular de la conducta y las ideas de los otros tratan de estructurar y modelar los significados. Sobre todo porque, la cuestión del significado está presente en relación con todos los diferentes momentos o prácticas de nuestro circuito cultural: en la construcción de la identidad, en la señalización de la diferencia, en la producción y el consumo, así como en la regulación de la conducta social. "En todas estas circunstancias y lugares institucionales, uno de los media privilegiados a través del cual se produce y circula el significado es el lenguaje" (HALL, 1997, p. 4).

\section{La importancia del significado en relación a la noción de cultura}

Lo que se ha denominado el 'giro cultural' en las Ciencias Humanas y Sociales, ha destacado la importancia del significado para la definición de cultura. La cultura, nos recuerda Stuart Hall (1997, p. 2) no sería tanto un conjunto de cosas como un proceso, un conjunto de prcticas. En primer lugar, la cultura tiene que ver con la producción y el intercambio de significados entre los miembros de una sociedad o de un grupo. Decir que dos personas pertenecen a la misma cultura es decir que interpretan el mundo de manera similar y que pueden expresar sus pensamientos y sentimientos sobre el mundo, de maneras que pueden ser entendidas por el otro. Así una cultura depende de cómo sus participantes interpreten significativamente lo que está pasando en torno a ellos, y que dan sentido al mundo de maneras similares. Esta definición de Hall es generosa y optimista: circunscribe la noción de cultura a una posibilidad de en- 
Elementos para una génesis de un campo de estudio de las prácticas culturales de la mirada y la representación

tendimiento mutuo y de compartir significados. La experiencia nos muestra que individuos que pertenecen a un mismo ámbito social no necesariamente comparten los mismos significados, y no digamos nada si no pertenecen al mismo ámbito, grupo de edad, género, etnia,... Lo cual no constituye una apelación al 'individualismo' pero si a la convivencia de diferencias junto a la utilización de 'patrones' (lo que los psicólogos denominan representaciones sociales) más o menos compartidos.

La cuestión de 'intercambiar significados' puede hacer aparecer a la cultura como algo demasiado unitario y cognitivo, sobre todo, porque en toda cultura hay siempre, como hemos visto en los apartados anteriores, una gran diversidad de significados sobre cualquier tema, y más de una manera de interpretarlos o representarlos. Sobre todo porque la cultura también tiene que ver tanto con sentimientos, vínculos y emociones como con conceptos o ideas. Stuart Hall (1997) ilustra esta cuestión recordándonos que

la expresión de mi cara dice algo sobre quien soy (identidad) y lo que estoy sintiendo (emociones) y a qué grupo siento que pertenezco (vínculo), lo cual puede ser comprendido por otras personas incluso si yo no intento comunicarme de forma deliberada con ellas, si no les envío un 'mensaje' o si la otra persona no pueda dar cuentas de lo que está comprendiendo de lo que estoy 'diciendo'.

Lo que nos lleva a considerar que los significados culturales no están solo en 'la cabeza', sino que organizan y regulan prácticas sociales, influencian nuestra conducta y por tanto, tienen efectos reales y prácticos (HALL, 1997, p. 2-3).

Pero lo que nos interesa para el campo de los ECV es el énfasis que Hall otorga a las 'prácticas culturales' en la medida en son los participantes en una cultura quienes dan significado a la gente, los objetos y los hechos. Hay que recordar que las cosas por sí mismas, raramente tiene un único, fijo y estable significado. Una piedra por ejemplo, puede ser una piedra, una marca en el camino, una pieza escultórica, depende de lo que signifique, de lo que quiere decir, dentro de un 'contexto de uso', dentro de lo que los filósofos (en especial Wiggestein) han denominado 'juegos de lenguaje' (en este ejemplo, el len- 
guaje de los límites, el lenguaje de la escultura). Es por el uso que hacemos de las cosas, y lo que decimos, pensamos o sentimos sobre ellas -cómo las representamos- que les damos un significado. En parte, nos recuerda Hall (1997)

damos a los objetos, las personas, los hechos significado por los marcos de interpretación a los que los llevamos. En parte, damos significado a las cosas por cómo las utilizamos o las integramos en las prácticas cotidianas. En parte, les damos significados a las cosas por cómo la 'representamos', mediante las palabras que utilizamos sobre ellas, las historias que contamos sobre ellas, las imágenes que producimos sobre ellas, las emociones que asociamos con ellas, las maneras cómo las clasificamos y conceptualizamos, los valores que colocamos en ellas. La cultura, está presente en todas estas prácticas que no están programadas genéticamente en nosotros, pero que tienen significado y valor para nosotros, que necesitan ser significativamente interpretadas por otros, y que dependen del significado para que operen efectivamente. La cultura, en este sentido, permeabiliza a toda la sociedad. Es lo que distingue el elemento humano en la vida social de lo que es biológico. Su estudio subraya el papel social del dominio de lo simbólico en el centro de la vida social (HALL, 1997, p. 3).

\section{La noción de 'representación' como campo de encuentro entre lengua y cultura}

Stuart Hall en su preocupación por el papel del significado en la construcción de las prácticas culturales y de la identidad, llega a la noción de representación cuando se pregunta "¿Qué relación tiene la representación con la cultura? ¿Cuál es la conexión entre ellas?" (HALL, 1997, p. 1) y responde recordando una definición de cultura que le ha acompañado en su transitar por los estudios culturales: "cultura se refiere a compartir significados". Enunciado que le da pie para situar el papel del lenguaje en la construcción de los significados y, por tanto, de la cultura. Para Hall

el lenguaje el medio privilegiado en el cual 'damos sentido', y en el cual el significado es producido e intercambiado. Los significados pueden ser sólo intercambiados a través de nuestro común acceso al lenguaje. Por tanto, el lenguaje es esencial para el signi- 
Elementos para una génesis de un campo de estudio de las prácticas culturales de la mirada y la representación

ficado y la cultura y es considerado como el depósito de valores y significados culturales (HALL, 1997, p. 1).

Para Hall, la forma más tradicional es la que considera a la cultura como "lo mejor que se ha pensado y dicho en una sociedad', cómo las grandes ideas han sido representadas en las obras clásicas de la literatura, la pintura, la música y la filosofía. Nos referimos en esta definición a la 'alta cultura' de una época" (HALL, 1997, p. 2).

Dentro del mismo marco de referencia, pero desde una aproximación más moderna, el uso de 'cultura' se refiere a las manifestaciones de música popular, publicidad, arte, diseño, literatura, $u$ otras actividades de tiempo libre y entretenimiento, que hacen la vida diaria de la mayoría de la 'gente corriente'. A esto se le llama 'cultura de masas' o 'cultura popular' de una época. Alta cultura versus cultura popular fue, durante muchos años, la manera de enmarcar el debate sobre la cultura, sobre todo, como hemos visto, desde la Sociología y los Estudios culturales.

Recientemente, y desde las ciencias sociales, la palabra 'cultura' se usa para referirse a cualquier cosa que hace referencia a la 'forma vida' (way of life) de una gente, comunidad, nación o grupo social. Esta sería la definición que utilizan en la actualidad los antropólogos, quienes emplean cada vez menos la noción de cultura y más la de formas de vida. También la palabra se puede usar para describir 'el intercambio de valores' de un grupo o sociedad, lo que sería seguir también, nos recuerda Hall, la definición antropológico, sólo que con un énfasis sociológico (HALL, 1997, p. 2).

Este preámbulo de puntualizaciones lleva a Hall a prestar especial atención a la relación entre significado, lenguaje y representación. Los miembros de una misma cultura han de intercambiar conceptos, imágenes e ideas que les permiten pensar y sentir sobre el mundo, y así interpretarlo de maneras similares. Deben intercambiar similares 'códigos culturales'. En este sentido, pensar y sentir son sistemas de representación en los cuales nuestros conceptos, imágenes y emociones representan en nuestra vida mental cosas que están o pueden estar 'fuera' en el mundo. De manera similar, para comunicar estos significados 
a otras personas, los participantes de cualquier intercambio significativo deben utilizar los mismos códigos lingüísticos, deben hablar 'la misma lengua'. Esto quiere decir que nuestros interlocutores debe hablar suficientemente la misma lengua para poder trasladar lo que 'tú' dices en lo que 'yo' comprendo y viceversa. También deben interpretar imágenes visuales, reproducir sonidos reconocidos como música, interpretar el lenguaje corporal y las expresiones faciales de manera similar. Deben saber cómo traducir sus sentimientos e ideas en estos lenguajes. Significado es diálogo, siempre entendido de manera parcial, siempre como un intercambio desigual.

¿Por qué nos referimos a todos estas diferentes maneras de producir y comunicar significados como lenguajes o que operan como lenguajes? ¿Cómo operan las lenguas? La respuesta simple es que las lenguas operan por medio de representacin, en la medida en que las lenguas son 'sistemas de representación'. Podemos decir que todas estas prácticas de significación operan como lenguajes, no porque sean escritas o hablados (que no lo son) sino porque utilizan el mismo elemento para representar lo que quieren decir, para expresar y comunicar un pensamiento, concepto, idea o sentimiento. La lengua hablada utiliza sonidos, la lengua escrita palabras, la música notas y escalas, el lenguaje del cuerpo gestos, la industria de la modas ropa, el lenguaje del rostro maneras de componerlo, la televisión usa puntos digitales o electrónicos en la pantalla, los semáforos usan rojo, verde y ámbar para 'decir algo'. Estos elementos (sonidos, palabras, notas, gestos, expresiones, vestidos) son parte de nuestro mundo natural y material. Pero su importancia como lenguaje no es lo que son sino lo que hacen, su función. Construyen y transmiten significado. Significan. No tienen un claro significado por sí mismos. Son vehículos o media que llevan significado porque operan como símbolos, que representan (simbolizan) los significados que queremos comunicar. Para utilizar otra metáfora, funcionan como signos. Los signos representan nuestros conceptos, ideas y sentimientos de tal manera que permite a otros 'leer', decodificar o interpretar su significado de una manera similar a como lo hacemos nosotros. 
Elementos para una génesis de un campo de estudio de las prácticas culturales de la mirada y la representación

\section{La relevancia de las 'formaciones discursivas' y las 'practicas de discurso'}

Al inicio de este recorrido apuntaba dos perspectivas dentro del Postesctructuralismo. La textual y la mundana. La que toma como referente a Barthes y sobre todo Derrida y la que sigue la senda Deleuze y, de manera especial, de Foucault. Como nos recuerda Barsky (1993, p. 34) el trabajo reciente en análisis del discurso realiza estudios en la estructura del discurso vinculados a fenómenos institucionales sociales e institucionales, y tiene una deuda especial con la obra de Foucault sobre el análisis enunciativo, las unidades de discurso y la formación discursiva, tal y como aparece en La Arqueologa del saber' (1969) y 'El orden del discurso' (1971) y en varias de sus obras en las que explora la articulación del conocimiento y del poder en el discurso como lo refleja en 'Vigilar y Castigar':

Hay que admitir más bien que el poder produce saber (y no simplemente favoreciéndolo porque lo sirva o aplicándolo porque sea útil); que poder y saber se implican directamente el uno al otro; que no existe relación de poder sin constitución correlativa de un campo de saber, ni de saber que no suponga y no constituya al mismo tiempo unas relaciones de poder (FOUCAULT, 1976 [1975], p. 34).

Hall (1997) llega a las posiciones discursivas, mediante su análisis de la relación que a través de la cultura y el lenguaje tiene lugar en la producción y circulación de sentido. Para Hall

La manera convencional nos dice que 'las cosas' existen en el mundo material y natural, que sus características naturales o materiales son las que los determinan o constituyen; y que tienen un claro significado fuera de como son representados. La representación es un proceso de importancia secundaria, que entra en el campo sólo después que las cosas han sido completamente formadas y sus significados constituidos. Pero en el 'giro cultural' en las ciencias humanas y sociales, el significado es producido, construido, más que simplemente "encontrado" (HALL, 1997, p. 5).

'El lenguaje' por tanto, facilita un modelo general sobre como operan la cultura y la representación, de manera especial en lo que se conoce como la perspectiva semiótica (la semióti- 
ca considerada como la ciencia de los signos y su papel como vehículos de significado en la cultura). En los últimos años, esta preocupación respecto al significado ha tomado un giro diferente, centrándose no en cómo opera el lenguaje, sino en el papel del discurso en la cultura. Desplazándose de la propuesta textual, a la propuesta mundana del postestructuralismo. Para Hall

discursos son maneras de referirse a o de construir conocimiento sobre un tema específico de la práctica: un conjunto de ideas, imágenes o prácticas que facilitan maneras de hablar sobre formas de conocimiento y conductas asociadas con un tema específico, una actividad social o un espacio institucional en la sociedad. Estas formaciones discursivas, definen lo que es y no es apropiado en nuestra formulación de, en nuestras prácticas en relación a, un tema concreto, o un espacio de actividad social, y en que tipo de personas o 'sujetos' personifican esas características. 'Discursivo' ha pasado a ser el término general utilizado para referirse a cualquier perspectiva en la que el significado, la representación y la cultura son considerados como constitutivos (HALL, 1997, p. 6).

A la hora del análisis de imágenes y las producciones de la cultura visual no tratamos tanto de explorar sus significados, sino interpretar el dispositivo que hace que opere como discurso, que se constituyan como prácticas discursivas, no sólo en el sentido señalado por Hall, sino también como regulador de prácticas y saberes. Esto es, en el sentido que da Foucault a la noción de discurso.

Hay algunas semejanzas, pero también diferencias, entre el enfoque semiótico y el discursivo. Una diferencia importante es que la perspectiva semiótica tiene que ver con el cmo de la representación, en cómo el lenguaje produce significado, lo que ha sido denominado su 'poética'. Mientras que la perspectiva discursiva tiene que ver con los efectos y consecuencias de la representación, su 'política'. La perspectiva discursiva presta atención no sólo a cómo el lenguaje produce significado, sino como el conocimiento que produce un particular discurso conecta con el poder, regula la conductas, fabrica o construye identidades y subjetividades, y define las maneras cómo ciertas cosas son representadas, pensadas, practicadas 
y estudiadas. El énfasis en la perspectiva discursiva está siempre en la especificidad histórica de una forma particular o de un 'régimen' de representación: no sobre el 'lenguaje' como una cuestión general, sino con lenguajes o significados específicos, y cómo se despliegan en un tiempo y un lugar concreto.

La utilización del lenguaje y el discurso como modelos sobre cómo la cultura, el significado y la representación opera, y el 'giro discursivo' que ha seguido en las ciencias humanas y sociales, es uno de los cambios de dirección más significativos en nuestro conocimiento de la sociedad que ha tenido lugar en los últimos años.

El debate postestructuralista, con su presupuesto de la primacía del discurso y de las prácticas lingüísticas, altera radicalmente las concepciones de la cultura. La perspectiva postestructuralista amplía por un lado los abordajes sociológicos (como los de orientación marxista o la teorización de Bourdieu, por ejemplo), centrados en una visión de la cultura como campo de conflicto y de lucha, pero por el otro lo modifica, al alejar el énfasis de una evaluación epistemológica (verdadero/falso) basada en la posición estructural del actor social, para los efectos de verdad inherentes a las prácticas discursivas. Dentro de esa visión, la cultura es un campo de lucha acerca de la construcción e imposición de significados sobre el mundo social (DA SILVA, 1998, p. 64-65)

Este giro discursivo está presente, en buena medida, en los ECV, en la medida en que la representación (visual) se puede analizar sólo de manera apropiada en relación a las actuales formas que el significado asume, en las prácticas concretas de significar, 'leer' e interpretar; estas prácticas requieren analizar los signos, símbolos, figuras, imágenes, narrativas, palabras y sonidos las formas materiales- en las cuales circula el significado simbólico.

\section{Aportaciones de los planteamientos postestructuralistas a los ECV}

De este breve esbozo en torno al Postesctructuralismo se deriva las siguientes consideraciones que son tenidas en cuenta en el campo de la cultura visual, y en algunas de sus aplicacio- 
nes metodológicas, como el análisis semiótico y el análisis del discurso.

- El significado del lenguaje no es dado ni fijo, sino construido por el sujeto que habla escribe o mira en contextos de intercambio cultural.

- Más que decir la verdad, la filosofía construye significados mediante la supresión, la exclusión o la marginalización de términos, por lo tanto, deberíamos desconstruir el texto y cualquier interpretación es igualmente válida.

- El poder opera a través de complejas estructuras sociales y se manifiesta en prácticas discursivas.

- Conocimiento y verdad son ideas que pueden cambiar de manera radical según las posiciones de los sujetos y las circunstancias históricas.

- La tarea de un desconstruccionista no es encontrar lo que el texto significa de manera objetiva, sino mostrar las contradicciones lingüísticas y exponer las relaciones de poder o las agendas políticas que se encuentran ocultas.

Todo ello nos lleva a concluir diciendo que el Postestructuralismo aporta a los ECV:

- Un marco para el análisis textual (entendido el texto desde una dimensión amplia), y discursivo, en relación a los contextos políticos y sociales en los que se produce y en los que opera.

- La redefinición de una teoría del signo en la que considera el "interpretante" de Peirce como nuevo "signo" creado por el intérprete en el proceso de entendimiento de los signos.

- La relación dialógica entre el texto y los lectores, basada en la teoría de la 'estructura dialógica' de lenguaje de Mijail Bajtín y en su propuesta de que son los individuos los que se intercambian signos que entrarán a formar parte de la ideología.

- La teora de la mirada de Lacan (como filtro en el campo de la visión, similar al del lenguaje en el de lo simbólico), ha insistido en la relación entre representación y espectador, en la que éste se 'sitúa' visual y psíquicamente en función de la construcción de aquélla, como signo que a su vez negaría una concepción perceptualista-ilusionista de la imagen.

- Frente a la teoría de la muerte del autor (Barthes) y del artis- 
ta, al preexistir a su intervención las convenciones del código, con la consiguiente disolución del autor en su producto y la negación de la idea de intenciones artística en el acto interpretativo, con Foucault insiste en el carácter histórico de la subjetividad y en la necesidad de contar con ella en los contextos históricamente pertinentes.

Estos tres recorridos permiten situar el origen de los conceptos, problemas y debates que se cruzan y nutren los ECV. Son elementos para una génesis teórica y metodológica de un campo de conocimientos que no se puede considerar como 'propio' de una disciplina, sino como cruce y reflejo de de un desplazamiento hacia lo cultural a la hora de investigar las tecnologías de la visión, las prácticas de visualidad y la posición de los visualizadores.

\section{Notas}

1- http://faculty.art.sunysb.edu/ nmirzoeff/.

2- http://educ.queensu.ca/ qbell/update/tint/postmodernism/postst.html.

3- Colocar a Benjamin en esta lista no deja de ser una generalización debido a su interés por lo visual, pero no porque este autor pueda ser ubicado dentro de la tendencia postesctructuralista.

4- Mi pregunta, desde la educación, sería quién y cómo se produce y construye el significado y cómo lo aprendemos. 


\section{Referencias}

ALPERS, S. (1987) [1983] El arte de describir. El arte holands en el siglo XVII. Madrid: Hermann Blume.

. (1996) Questionnaire on Visual Culture. October, 77, 26.

BARSKY, R. (1993) Discourse analysis. En I.R. Makarik (Ed.) Encyclopedia of Contemporary Literacy Theory. (pp.35-36).Toronto: University of Toronto Press.

BAXANDALL, M. (1978) [1972] Pintura y vida cotidiana en el Renacimiento. Barcelona: Gustavo Gili. . (1996) [1971] Giotto y los oradores. Madrid: Visor.

BIRD, J. (1986) On Newness, art and History. Reviewing Block 1979-1985. En L. Ress \& F. Borzenllo, (Eds.) The New Art History. Londres: Camden Press.

BREA, J. L. (Ed.) (2005) Estudios Visuales. La epistemologa de la visualidad en la era de la globalizacin. Madrid: Akal.

BRYSON, N. (1991) [1983] Visin y pintura. La lgica de la mirada. Madrid: Alianza.

CLARK, T. J. (1973) The absolute bourgeois: artists and politics in France, 18481851. Greenwich, Conn.: New York Graphic Society.

. (1981 [1973] ) Imagen del pueblo. Gustave Courbet y la Revolucin de 1848. Barcelona: Gustavo Gili.

FOUCAULT, M. (1976) [1975] Vigilar y castigar. México: Siglo XXI.

GRAMSCI, A. (1972) Los intelectuales y la organizacin de la cultura. Buenos Aires: Nueva Visión.

CRARY, J. (1990) Techniques of the observer. Cambridge, Mass: MIT Press.

DA SILVA, T.T. (Org.) (1995) Aliengenas na sala de aula. Uma introduo aos estudos culturais em educao. Petrópolis, RJ: Vozes.

(1998) Cultura y currículum como prácticas de significación. Revista de Estudios del Currculum, 1, (1), 59-76.

DEBORD, G. (1999) [1967] La Sociedad del espectculo. Valencia : Pre-textos.

DIKOVITSKAYA, M. (2005) Visual Culture. The Study of the Visual after the Cultural Turn. Cambridge, MA: MIT Press.

DUNCUM, P. (2001) Visual Culture: Developments, Definitions, and Directions for Art Education. Studies in Art Education, 42 (2), 101-102.

ELKINS, J. (2003) Visual Studies. A Skeptical Introduction. Nueva Cork y Londres: Routledge.

EVANS, J. \& HALL, S. (Eds.) (1999) Visual Culture: the reader. Londres: Sage.

FOSTER, H. (1988) Preface. En H. Foster (ed.) Vision and visuality. (p. ix-xiv) 
Elementos para una génesis de un campo de estudio de las prácticas culturales de la mirada y la representación

New York: The New Press.

FREEDMAN, K. (2000) Social Perspectives on Art Education in the U.S.: Teaching Visual Culture in a Democracy. Studies in Art Education, 41 (4), 314-329.

HALL, S. (1980) Cultural Studies at the Centre: Some problems and problematics. En S. Hall, D. Hobson, A. Lowe y P. Willis (Comps.) Culture, Media, Language, (p. 15-47) Londres: Hutchinson

(Ed.) (1997) Representation: Cultural Representations and Signifying Practices. Milton Kynes: Open University.

. (2000) [1992] Los estudios culturales y sus legados teóricos. Voces y Culturas, 16, 9-27.

HERNÁNDEZ, F. (en prensa, a) Los Estudios de Cultura Visual: La construcción permanente de un campo no disciplinar. Revista Internacional de Arte y Diseo La Puerta. Universidad de La Plata. Argentina.

- (en prensa, b) ¿De qué hablamos cuando hablamos de Cultura Visual? Construir una historia cultural de las miradas. Educao \& Realidade. . (en prensa, c) Espigador@s de la cultura visual. Barcelona: Octaedro. HALL, Stuart (Ed.) (1997) Representation: Cultural Representations and Signifying Practices. Milton Kynes: Open University.

HEYWOOD, Ian. \& SANDWELL, Barry (Eds.). (1999) Interpreting Visual Culture. Explorations in the hermeneutics of vision. Londres: Routledge.

KRESS, G. (2003) Literacy in the New Media Age. London: Routledge.

LACAN, J. (1971) [1996] El estadio del espejo como formador de la función del yo tal y como se nos revela en la experiencia psicoanalítica. En Escritos 1. (p.1120) México: Siglo XXI.

MARÍAS, F. (1996) Teora del arte II. Madrid: Historia 16.

MIRZOEFF, Nicholas. (1998) What is visual culture? En N. Mirzoeff (ed.) Visual Culture Reader. (p.3-13). Londres: Routledge.

(2003) [1999] Introduccin a la cultura visual. Barcelona: Paidós.

MITCHELL, W.J.T. (2000a) [1995] Interdisciplinariedad y cultura visual. Jornadas Ms all de la educacin artstica. Cultura visual, poltica de reconocimiento y educacin. Barcelona: Fundación La Caixa: 5 y 6 de noviembre. Traducción del texto Interdisciplinarity and Visual Culture. Art Bulletin, 4, (77) (Diciembre).

(2000b) [1995] ¿Qué es la cultura visual? Jornadas Ms all de

la educacin artstica. Cultura visual, poltica de reconocimiento y educacin. Barcelona: Fundación La Caixa, 5 y 6 de noviembre. Traducción del texto What Is Visual Culture?" En Irving Lavin (Ed.)Meaning in the Visual Arts: Essays in Honor of Erwin Panofskys 100th Birthday, (p. 207-217) Pricenton: Institute for Advance Studies.

POINTON, M. (1986) History of Art and the Undergraduate Syllabus. Is It a 
Disciplina and How Should We teach It? En A.L. Rees y F. Borzello (eds.) The New Art History. Londres: Camden Press.

Routledge.

(1994) [1980] History of Art. A students handbook. Londres:

REES, L. \& BORZELLO, F. (Eds.) (1986) Introduction. En The New Art History. Londres: Camden Press.

ROGOFF, I. (1998) Studying visual culture. En N. Mirzoeff (Ed.) The Visual Culture Reader. Londres: Routledge.

RUSSELL, S. (1988) California Q\&A: A Conversation with Svetlana Alpers. California Monthly (Sept. 1988).

SARDAR, Z. y VAN LOON, B. (1997) Cultural Studies for Beginners. Cambridge: Icon Books.

WILLIAMS, R. (1976) Keywords: A vocabulary of Culture and Society. Londres: Croom Helm.

(1989) The Future of Cultural Studies. The Politic of Modernity. (pp.151-162).London: Verso.

\section{FERNANDO HERNÁNDEZ}

é Doutor em Psicologia e Professor Titular do Departamento de Desenho da Faculdade de Belas Artes da Universidade de Barcelona, Espanha. Coordena o Programa de Doutorado em Artes Visuais e Educação e Mestrado em Estudos da Cultura Visual. No Brasil, publicou os seguintes livros: Transgressão e mudança na educação, Organização do Currículo por Projetos de Trabalho (com Montserrat Ventura), Tecnologias para Transformar a Educação (com Juana Sancho) e Catadores da Cultura Visual. 